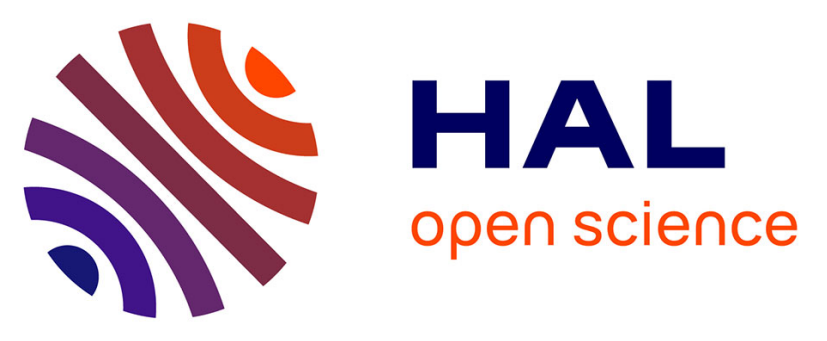

\title{
Two persistent organic pollutants which act through different xenosensors (alpha-endosulfan and 2,3,7,8 tetrachlorodibenzo-p-dioxin) interact in a mixture and downregulate multiple genes involved in human hepatocyte lipid and glucose metabolism.
}

Ariane Ambolet-Camoit, Chris Ottolenghi, Alix Leblanc, Min Ji Kim, Franck

Letourneur, Sébastien Jacques, Nicolas Cagnard, Christiane

Guguen-Guillouzo, Robert Barouki, Martine Aggerbeck

\section{To cite this version:}

Ariane Ambolet-Camoit, Chris Ottolenghi, Alix Leblanc, Min Ji Kim, Franck Letourneur, et al.. Two persistent organic pollutants which act through different xenosensors (alpha-endosulfan and 2,3,7,8 tetrachlorodibenzo-p-dioxin) interact in a mixture and downregulate multiple genes involved in human hepatocyte lipid and glucose metabolism.. Biochimie, 2015, 116, pp.79-91. 10.1016/j.biochi.2015.07.003 . hal-01174215

HAL Id: hal-01174215

https://hal-univ-rennes1.archives-ouvertes.fr/hal-01174215

Submitted on 16 Sep 2015

HAL is a multi-disciplinary open access archive for the deposit and dissemination of scientific research documents, whether they are published or not. The documents may come from teaching and research institutions in France or abroad, or from public or private research centers.
L'archive ouverte pluridisciplinaire HAL, est destinée au dépôt et à la diffusion de documents scientifiques de niveau recherche, publiés ou non, émanant des établissements d'enseignement et de recherche français ou étrangers, des laboratoires publics ou privés. 
Two persistent organic pollutants which act through different xenosensors (alphaendosulfan and 2,3,7,8 tetrachlorodibenzo-p-dioxin) interact in a mixture and downregulate multiple genes involved in human hepatocyte lipid and glucose metabolism

Ariane Ambolet-Camoit ${ }^{1,2, \mathbb{I}}$, Chris Ottolenghi ${ }^{1,2,3 \text {, II }}$, Alix Leblanc ${ }^{1,2}$, Min Ji Kim ${ }^{1,2}$, Franck Letourneur $^{2,4}$, Sébastien Jacques ${ }^{2,4}$, Nicolas Cagnard ${ }^{2,4}$, Christiane GuguenGuillouzo $^{5,6}$, Robert Barouki ${ }^{1,2,3}$ and Martine Aggerbeck ${ }^{1,2, *}$

${ }^{1}$ Inserm UMR-S 1124, Paris, France

${ }^{2}$ Université Paris Descartes, Sorbonne Paris Cité, Paris, France

${ }^{3}$ APHP, Hôpital Necker Enfants Malades, Service de Biochimie Métabolique, Paris, France

${ }^{4}$ Plateforme de Génomique, Institut Cochin, Paris, France

${ }^{5}$ Université de Rennes 1, Rennes, France

${ }^{6}$ Inserm, UMR991, Rennes, France

* Corresponding author. UMR-S 1124 INSERM, Centre universitaire des Saints-Pères, Université Paris Descartes, 45 rue des Saints-Pères 75006 Paris, France.

Tel : 33 (0)142862093. E-mail address : martine.aggerbeck@ parisdescartes.fr

${ }^{\text {II }}$ Both authors contributed equally to the manuscript 


\section{Abstract}

Individuals, typically, are exposed to mixtures of environmental xenobiotics affecting multiple organs and acting through different xenosensors and pathways in species and celltype specific manners. 2,3,7,8-tetrachlorodibenzo-p-dioxin (TCDD) and $\alpha$-endosulfan are Persistent Organic Pollutants (POPs) and endocrine disruptors which act through different xenosensors and accumulate in the liver. Our objective in this HEALS study was to investigate the effects of the mixture of these POPs on gene expression in a human-derived hepatocyte cell line, HepaRG. We found that, in spite of having largely uncorrelated effects, TCDD and $\alpha$-endosulfan, when mixed, alter the expression of genes. The combined effects of the mixture of the POPs significantly altered the expression of 100 genes (42 up- and 58 down-regulated) whereas the same concentration of either POP alone did not alter significantly the expression of these genes. For 32 other genes, selective inhibitory crosstalk between TCDD and $\alpha$-endosulfan was observed. One of the POPs inhibited the effect, on gene expression, of the other in the mixture although, when used alone, that POP did not affect expression. The expression of another 82 genes was significantly altered (up- or downregulated) by a single POP. The addition of the second POP either increased, in the same direction, the effect on gene expression or had no further effect. At low concentrations (0.2nM TCDD and $1 \mu \mathrm{M} \alpha$-endosulfan), the POPs still had significant effects and the levels of expression of the corresponding proteins were found to be affected for some genes. Particularly striking was the $80-90 \%$ inhibition, by the mixture, of the expression of a number of genes of several hepatic intermediary metabolic pathways (glycerolipid metabolism, FXR/RXR activation, glycolysis/gluconeogenesis, retinoid and bile acid biosynthesis), whereas each pollutant alone had only a moderate effect.

Keywords: dioxin, pesticides, HepaRG, mixture, metabolism, microarray 


\section{Introduction}

Environmental exposure to toxic chemicals for most individuals involves mixtures of compounds and extended periods of exposure. Humans are exposed not only to pesticides (estimated use exceeding 3 billion tons per year worldwide), mainly through food consumption, but also to a variety of other environmental xenobiotics, many of them being endocrine disrupters, which may have a variety of detrimental effects on human health $[1,2]$. Epidemiological studies often associate occupational exposure to these compounds with an increase in the incidence of various pathologies, including cancers, neuro-degenerative disorders, reduced fertility and the metabolic syndrome which can lead to type 2 diabetes [310]. Although concerns about the adverse effects of mixtures of chemicals and their potential interactions are increasing, especially for vulnerable populations, most studies on the effects of pollutants to date have focused on exposure to a single compound or to a mixture of compounds that act through the same signaling pathway. Only a few studies [11-19] have addressed the toxicity of mixtures of contaminants which act through different xenosensors, even though combinations of different chemicals, especially at low levels of exposure, probably have significant effects on human health [20, 21].

In this study, part of the HEALS exposome European project, we investigated the effects of a mixture of two endocrine disruptors, 2,3,7,8-tetrachlorodibenzo-p-dioxin (TCDD) and $\alpha$-endosulfan, which act via different signalling pathways, accumulate in the liver and may have non-cancerogenic toxic hepatic effects in humans [22-25]. TCDD is one of the most potent ligands of the aryl hydrocarbon receptor (AhR) and a classical one with little metabolism and a half-life of about 7 years in humans, which triggers several biological responses [1]. Alpha-endosulfan is the major isomer of an organochlorine insecticide known to act through two different signalling pathways, the pregnane $X$ receptor (PXR) $[26,27]$ or the estrogen receptor $\alpha(\operatorname{ER} \alpha)[12,28]$. Although endosulfan use has been banned in many 
countries, it is still in use in China and India and decades of agricultural use have built up soil reservoirs [17]. Endosulfan sulfate, which is a major metabolite of $\alpha$-endosulfan is as toxic as the parent compound and more persistent with a half-life of months to years in soils, sediments and water [22, 23]. Moreover, since dioxins are by-products of chlorinated compounds, both pollutants can be associated during pesticide manufacturing. In vivo, pollutant induced toxic effects on the liver arise from direct effects on hepatocytes and from extra-hepatic factors. Among extra-hepatic factors that may alter hepatocyte function, the disruption of the endocrine system [29, 30] or pollutant induced modification of the environment of the organ may affect hepatic physiology. This may be due to the release of pro-inflammatory cytokines into the systemic circulation, the activation of hormonal or oxidative stress responses and hypoxia [31-37].

The objective of this study was to investigate the effects, related specifically to hepatocyte cell functions, of the mixture of TCDD and $\alpha$-endosulfan, by studying global gene expression in a human-derived hepatocyte cell line, HepaRG.

To our knowledge, few studies have explored the effects on global gene expression of a combination of two Persistent Organic Pollutants (POPs), which act through different xenosensors, using a human liver cell model. HepaRG cells were chosen for the study because, after differentiation, they express high levels of several xenobiotic metabolizing enzymes and xenosensors [38] and, to date, it is the human cell line that most closely resembles human hepatocytes $[39,40]$. A recent transcriptomic study, using five carcinogens, revealed that the HepaRG model was better suited for understanding the biological effects of exposure to the chemicals as compared to the HepG2 hepatocarcinoma cell line which has a low metabolic capacity and reduced PXR level [41-43]. Several other studies also have concluded that the HepaRG cell line is an excellent in vitro model to study human drug metabolism [39, 44-46] as well as being a relevant model for studying glucose, lipid and 
lipoprotein metabolism [47, 48]. The use of the HepaRG cell line, which also exhibits stable and inducible enzyme expression over long periods (weeks), and has reduced variability, thus avoids many of the difficulties associated with the use of human hepatocytes such as scarce availability, complicated isolation procedures, variability, rapid dedifferentiation precluding long term use and cost [49-52].

This study was designed to provide information on the combined effects of TCDD and the pesticide $\alpha$-endosulfan on genome-wide gene expression in one of the most relevant human hepatic cell lines, and to provide new data on the hepatic perturbations which may be linked to exposure to mixtures of persistent organic pollutants. 


\section{Materials and Methods}

\subsection{Compounds, cell culture, viability and treatments}

The chemical compounds that were used in this study, 2,3,7,8 tetrachlorodibenzo-pdioxin or TCDD (PubChem CID: 15625) and $\alpha$-endosulfan (PubChem CID: 3224), were obtained from LGC Standards (France). HepaRG cells, obtained from Dr. Guguen-Guillouzo [53], were differentiated as described previously except that $1.5 \%$ DMSO was used for cell differentiation [54]. DMSO was removed from the medium for twenty-four hours before treating the cells for 30 hours with $25 \mathrm{nM}$ TCDD, $10 \mu \mathrm{M} \alpha$-endosulfan, the mixture of the two pollutants (at the above concentrations) or the vehicle (0.15\% DMSO). The viability of the cells was evaluated using the WST-1 kit (Roche Applied Science). For some experiments, the cells were treated for 8 days with lower concentrations of the compounds $(0.2,0.5,1$ or $5 \mathrm{nM}$ TCDD and 1 or $3 \mu \mathrm{M} \alpha$-endosulfan) with only two changes of medium containing the compounds during this period (day 0 and day 4) to minimize any build up in the concentrations of the chemicals due to binding of the xenobiotics to the plastic of the culture dishes.

\subsection{RNA preparation and microarray hybridization}

RNA from the HepaRG cells was prepared using the RNeasy mini kit from Qiagen (France) as described previously [55] except that a DNase I step was included in the protocol. For the microarray studies, the quality of the RNA (RIN value) was assessed with a Bionalyzer (Agilent Technologies) [56].

ssDNA (sense single stranded DNA) was synthesized using the Affymetrix GeneChip Whole Transcript Sense Target Labelling Assay kit, according to the manufacturer's protocol. ssDNA samples were then fragmented according to the Affymetrix protocol. The purified ssDNA was quantified and its quality was assessed with a Bioanalyzer. Subsequent 
labeling of the samples was performed by synthesis of Biotin-labeled ssDNA using the GeneChip WT Terminal Labeling kit (Affymetrix). ssDNA targets were hybridized onto high-density microarrays (Affymetrix Human Genome 1.0 ST GeneChip array) according to the Affymetrix Eukaryotic Target manual. The microarrays were then washed and stained using the Affymetrix fluidics station 450/250 and Genechip Operating Software and scanned with an Affymetrix GeneArray scanner. The raw affymetrix datasets (.CEL) are available in the Gene Expression Omnibus database (http://www.ncbi.nlm.nih.gov/geo/) with the accession number (GSE46874).

\subsection{Microarray analyses}

Quality controls, including scaling factors, average intensities, background intensities, noise (raw Q) values were within acceptable limits for all the arrays. The twelve datasets obtained were processed and normalized using the plier program in R. Two different statistical analyses were performed: 1) we determined which genes were significantly differently expressed ( $\mathrm{p} \leq 0.05$ by $\mathrm{t}$-test, $>2$ fold difference) following exposure of cells to TCDD, $\alpha$-endosulfan or the mixture of the two as compared to the vehicle (DMSO), 2) we used the Focus software [57], as described by Garcia-Ortiz [58] to select genes that had at least a 1.2-fold mean difference in expression and a default "interest score" of $>5$. Principal component analysis (PCA) was carried out using the svd module in R. Hierarchical clustering analysis was performed with the Genepattern software [59] on the statistical scores derived from the Focus analysis rather than on the expression levels in order to reduce data variability.

Gene Set Enrichment Analysis (GSEA, http://www.broadinstitute.org/gsea/index.jsp) was used to test (using a metric derived from the Kolmogorov-Smirnov statistic [60, 61]) 
whether the distribution of the genes in our study deviated from random in ranked lists of genes up or down regulated by TCDD or $17 \beta$-estradiol. Rank-rank hypergeometric overlap was also used to identify statistically significant overlap between gene expression signatures [62]. The lists of genes were derived from an analysis of publicly available (literature or public repositories) genome-wide expression data obtained from exposure of primary human hepatocytes [63, 64], HepaRG [42] or mouse primary hepatocytes [65] to TCDD or 17ßestradiol. Raw data were renormalized with the plier module in $\mathrm{R}$ and robust averages calculated with Tukey's Bi weight average algorithm [66]. One way analysis of variance (ANOVA) was calculated for each pair of treatment groups and for all treatment groups. FDR were calculated by the Benjamini-Hochberg approach [67]. Differentially expressed genes were those having a fold change $>2$ and $p<0.05$. The data from supplementary files 11 and 17 from Forgacs et al. [64] were filtered as indicated in the files. Murine expression data from Flaveny et al. [65] were also analyzed with Focus. Genes were ranked according to Focus scores and filtered to retain only those showing a differential expression with t-test $\mathrm{p}$-values less than 0.20 on log ratios. The genes with the highest Focus scores (165 and 195 genes upand down-regulated, respectively, by TCDD) were selected as the gene sets to be compared with our samples. Exact area-proportional Euler diagrams were calculated and drawn with eulerAPE [68].

\subsection{Functional analysis}

Biological functions and pathways were generated from the Focus lists of genes up- or down-regulated by TCDD plus $\alpha$-endosulfan (as compared to either DMSO, TCDD or $\alpha$ endosulfan alone) and analyzed using Ingenuity Pathway Analysis v.8.3-3003 (IPA, Ingenuity Systems, CA). 


\subsection{Quantitative reverse transcriptase PCR}

A selected set of genes was analyzed by RT-qPCR using cDNA prepared from the 3 independent culture replicates used for the microarray experiments. The PCR primers used are listed in Table S1. Reverse transcription and quantitative PCR were performed as previously described [55].

\subsection{Western blotting}

Cells were scraped into $1 \mathrm{X}$ PBS buffer, containing $1 \%$ Nonidet P-40, $0.5 \%$ sodium deoxycholate and $0.1 \%$ SDS, protease and phosphatase inhibitors (Sigma). After freezing at $80^{\circ} \mathrm{C}$, the cells were thawed and centrifuged $10 \mathrm{~min}$ at $9000 \mathrm{~g}$ at $4^{\circ} \mathrm{C}$. The protein concentration in the supernatant was measured using the bicinchoninic acid method (Pierce) with BSA as a standard. The supernatant was aliquoted and kept at $-80^{\circ} \mathrm{C}$. Equal amounts of total proteins were separated by SDS-PAGE and transferred onto nitrocellulose membranes. Blocking of the membrane was performed using Odyssey buffer (LI-COR, ScienceTec, Courtaboeuf, France) for 1 hour at room temperature followed by incubation overnight at $4^{\circ} \mathrm{C}$ with a primary antibody directed against ADH1 (Acris AP16311PU-N, 1/1 000) or $\beta$-actin (Abcam 8227, 1/10 000). After three washes with $0.1 \%$ Tween-20 in $1 \mathrm{X}$ PBS, the membrane was incubated with either an anti-goat (IRdye 800 number 926-32214 LI-COR, ScienceTec, 1/15 000) or an anti-rabbit (IRdye 800 number 926-32211 LI-COR, ScienceTec, 1/10 000) secondary antibody. After three washes (0.1\% Tween-20 in $1 \mathrm{X}$ PBS), signals were quantified using the Odyssey infrared Imager (LI-COR, ScienceTec). 


\section{Results}

\subsection{Global gene expression in HepaRG cells treated with TCDD and $\alpha$ - endosulfan}

The concentrations of TCDD $(25 \mathrm{nM})$ and $\alpha$-endosulfan $(10 \mu \mathrm{M})$ were chosen so as to maximize the activation of the corresponding signalling pathways and, thus, to increase the number of genes that are differentially expressed. To assess the overt toxicity of these concentrations, the viability of the differentiated HepaRG cells was measured and was found not to be significantly different following exposure for 72 hours to the mixture or to either POP alone as compared to the $0.15 \%$ DMSO vehicle (Figure S1, A) or for up to 8 days at lower concentrations of the POPs (Figure S1, B). These concentrations were, therefore, used to investigate the effects of the POPs on global gene expression.

Principal component analysis (PCA) of the global variation in transcription of the HepaRG genome following exposure to the mixture or to each pollutant alone leads to several conclusions. First, the samples clustered by condition, which demonstrates that there is a significant difference in the transcription profiles that resulted from exposure to either POP alone or the mixture (Figure 1). Further, the samples treated with TCDD (alone or in combination with $\alpha$-endosulfan) consistently mapped to one side of the first principal component (55\% of the variability). Alpha-endosulfan-treated samples mapped to one side of the second principal component (20\% of the variability). The first principal component, PC1, thus accounts mainly for the effects of TCDD and the second principal component, PC2, for the effects of $\alpha$-endosulfan. Second, the major effects of TCDD and $\alpha$-endosulfan are largely uncorrelated because the corresponding PCA axes are orthogonal. This result is consistent with these compounds exerting their effects by different mechanisms (pathways) and with our current knowledge of the actions of these pollutants. Third, although the major effects of TCDD and $\alpha$-endosulfan are largely uncorrelated, the principal component analysis also 
clearly demonstrates that the effects of the mixture of $\alpha$-endosulfan and TCDD are greater than those of TCDD alone as shown by the significant difference $(\mathrm{p}<0.05$, post-Anova Tukey's test) in the mean PC1 values of the corresponding groups. Thus, in general, $\alpha-$ endosulfan exacerbates the effects of TCDD in the same direction of change that is most strongly associated with TCDD.

We next analyzed the global transcription data for differentially expressed genes using stringent criteria $(\mathrm{p} \leq 0.05,>2$-fold difference in expression for up-regulated genes and $<0.5$ fold for down regulated genes). The mixture of pollutants significantly altered the expression of 182 annotated genes, whereas TCDD and $\alpha$-endosulfan altered the expression of 98 and 23 genes, respectively, as compared to the DMSO vehicle. A Euler diagram shows that the 214 unique genes corresponding to the three treatments can be divided into 7 ensembles (Figure 2).

First, the two ensembles labelled A, B are remarkable in that 21 genes (ensemble A) were modified only following treatment of the cells with TCDD and 10 genes (ensemble B) were modified only following treatment with $\alpha$-endosulfan (Figure 2, Table S2). Intuitively, one would expect that if the expression of a gene was altered following treatment of the cells with a pollutant individually, then treatment with a mixture containing that pollutant would also affect the expression of the gene. However, in this case, although each pollutant significantly alters the expression of certain genes when present alone, the presence of the other POP in the mixture abolishes this effect (that is, the expression of the gene is no longer found to be significantly differentially expressed by the mixture of the pollutants). This suggests that inhibitory cross-talk occurs between the pollutants at the level of gene expression. It is important to note that the POP that is inhibitory in the mixture is not identified as significantly altering the expression of the gene when used alone. This aspect distinguishes ensembles A and B from ensemble C. The single gene in this ensemble (serine 
dehydratase) was significantly modified by either TCDD (61\% decrease in expression) or $\alpha$ endosulfan (6.37-fold increase in expression), individually, but in opposite directions, and, thus, the gene not being differentially expressed in the mixture (1.66-fold). Second, an ensemble of 100 genes (ensemble D) is identified only after treatment of the cells with the mixture of the POPs (Figure 2, Table S2). That is, the expression of each of these genes is not significantly altered following exposure of HepaRG cells to either TCDD or $\alpha$-endosulfan alone but only to the mixture of the pollutants. Thus, although treatment with either POP alone may not result in a significant effect (according to the stringent criteria adopted for identifying differentially expressed genes), the mixture of the POPs does result in significant alteration in gene expression. Since the experiment was not designed to evaluate additivity or synergy of effects, no conclusions can be drawn in this respect although the fold changes in expression found for the genes altered by the mixture are not markedly different from the sums of the fold changes in expression obtained following exposure to each pollutant alone.

Third, two other ensembles are composed of genes which are differentially expressed by cells following exposure to either TCDD or the mixture of TCDD and $\alpha$-endosulfan (70 genes, ensemble E, Figure 2, Table 1) or to $\alpha$-endosulfan or the mixture (6 genes, ensemble F, Figure 2, Table 1). Thus, exposure to one pollutant results in a significant change in gene expression and the addition of the second pollutant does not modify this effect as in ensembles A, B and C. For most of the genes in ensembles E and F, TCDD and $\alpha$-endosulfan exert their effects in the same direction (either both increasing or both decreasing gene expression). For some genes, TCDD seems to exert the major effect and $\alpha$-endosulfan does not further alter the expression of the gene. Finally, for some genes, $\alpha$-endosulfan diminishes somewhat the effect of TCDD and for one gene, GPX2, TCDD appears to diminish the effect of $\alpha$-endosulfan (similar to the inhibitory cross-talk described for ensembles A, B and C). However, in all cases, the effect of the second pollutant is not sufficient to eliminate the gene 
from the list of differentially expressed genes in contrast to what is observed for the genes in ensembles in A, B and C. Although the effect observed in ensembles $\mathrm{E}$ and $\mathrm{F}$ resembles that observed in ensembles A, B and C, the mechanisms involved are not necessarily the same.

The final ensemble, G, is composed of 6 genes (Figure 2, Table 2) which are differentially expressed $(\mathrm{p}<0.003-0.00001)$ following all of the treatments (TCDD or $\alpha$ endosulfan alone or the mixture). Interestingly, as opposed to all the other ensembles in which both increases and decreases in gene expression are found, this ensemble is composed of genes in which only a decrease in expression is observed and bothTCDD and $\alpha$-endosulfan exert their effects in the same direction.

In a second approach to identify differentially expressed genes, we ranked genes using a combination of multivariate and pairwise comparisons among all the conditions using somewhat less stringent conditions (a cutoff of 1.2 for the fold change and a Focus score of 5, followed by a two-tailed t-test, $\mathrm{p}<0.05)$. Exposure of HepaRG cells to the mixture of pollutants altered, to a greater extent, the expression of 662 annotated genes (558 upregulated and 104 downregulated) as compared to exposure to either chemical alone. An additional 289 non-annotated transcripts were also found (211 up- and 78 down-regulated). The top 10 upand 10 down-regulated genes are listed in Table 3.

We then compared the list of those 20 genes (top 10 up- and down-regulated genes) with the list of genes identified with the stringent conditions (stringent t-test analysis). Five genes (indicated by bold type in Table 3) were found in the genes regulated following treatment with the mixture only (Table S1). Nine other genes are common to the list of genes whose expression is altered following exposure to TCDD alone and the mixture (Table 1 and * in Table 3 ) or to $\alpha$-endosulfan alone and the mixture (CYP 2E1, see Table 1). Finally, 3 genes $\left({ }^{\$}\right.$ in Table 3$)$ are found on the list of genes that were found to be altered by exposure to all 3 treatments (Table 2). Since the expression of the remaining 3 genes of the Focus list 
varied less than 2-fold, they were not present in the stringent analysis. The results of the Focus analysis were, thus, in good agreement with the more stringent analysis used to identify genes that discriminate the effect of exposure to the mixture from that of exposure to a unique POP.

Hierarchical clustering (HC) analysis of the Focus scores of the differentially expressed genes demonstrates that the gene expression profile for HepaRG cells exposed to the mixture of pollutants clusters with that of cells exposed to TCDD alone in agreement with the PCA analysis. The HC analysis also shows that large clusters of genes are more strongly up-regulated (Figure 3A, intense red color in black box) or down-regulated (Figure 3B, deep blue color in black box) in cells following exposure to the mixture as compared to exposure to a single POP.

\subsection{Correlation between the microarray, RT-qPCR and immunoblotting} technologies

Reverse transcriptase quantitative polymerase chain reaction (RT-qPCR) was used as an independent, confirmatory, technique to evaluate the expression of a subset of the genes found to be differentially expressed by global genome expression analysis. We measured the expression of 30 genes, 11 up-regulated genes and 19 down-regulated. These genes, taken together, exhibit a large range of fold changes, as assessed by whole genome analysis, following exposure of cells to the mixture of the POPs or to dioxin and $\alpha$-endosulfan alone (Table S3). The values for the expression of the genes obtained by micrarray analysis and RT-qPCR are highly correlated $\left(\mathrm{R}^{2}=0.97,0.90\right.$ and 0.97 for treatment by TCDD alone, $\alpha$ endosulfan alone or the mixture, respectively, Figure S2) suggesting that the global gene results are trustworthy. 
To determine whether exposure to lower concentrations of the POP mixture for longer periods of time exhibited the same effects, we exposed HepaRG cells for 8 days to lower concentrations of TCDD $(0.2 \mathrm{nM}$ to $5 \mathrm{nM})$ and a 10-fold lower concentration of $\alpha$-endosulfan $(1 \mu \mathrm{M})$ and to the various mixtures. We examined the expression of two genes (ADH1B and G6PC), the expression of which was severely downregulated with the highest concentrations previously tested. ADH1B gene expression was markedly decreased after treatment with $5 \mathrm{nM}$ TCDD and G6PC gene expression was already decreased at the lowest TCDD concentration tested (0.2nM TCDD). Although a concentration of $1 \mu \mathrm{M} \alpha$-endosulfan did not affect significantly the expression of either ADH1B (no effect) or G6PC (40\% decrease), the mixture of the POPs decreased the expression of both genes significantly more as compared to the effect of TCDD alone. (Figure 4A). Alteration in the expression of the gene may be followed by an effect on the level of the protein present in the cells, as shown by the decrease in the amount of ADH1 (Figure 4B), after 3 days of exposure to the POPs (5 or 25nM TCDD, $10 \mu \mathrm{M} \alpha$-endosulfan or their mixtures.

\subsection{Pathways regulated by the mixture of TCDD and $\alpha$-endosulfan}

To elucidate the effects on hepatocyte function following exposure of HepaRG cells to the combination of the two pollutants, we used Ingenuity Pathway Analysis (IPA) to assign the biological pathways altered by the different treatments. The 4 top network functions associated with the genes regulated by the mixture of TCDD and $\alpha$-endosulfan using the Focus analysis were: i) RNA post-transcriptional modification, genetic disorder, lipid metabolism; ii) cancer, gastrointestinal disease, genetic disorder; iii) molecular transport, RNA trafficking, cell cycle; iv) small molecule biochemistry, DNA replication, recombination, repair, cell cycle. The lipid metabolism, small molecule biochemistry and molecular transport networks were the top networks associated with genes that were down- 
regulated whereas the other key words were mostly associated with up-regulated genes. The associated canonical pathways are given in Table 4. The farnesoid $\mathrm{X}$ receptor/retinoid $\mathrm{X}$ receptor (FXR/RXR), bile acid biosynthesis and glycerolipid metabolism pathway genes were down-regulated, as were genes in the glycolysis/gluconeogenesis pathway. The top down-regulated network by the mixture of TCDD and $\alpha$-endosulfan (as well as the top molecular and cellular functions network), "lipid metabolism", derived by the Ingenuity network analysis $(\mathrm{p}<0.00001)$ contains the genes shown in Table S4. Only the 11 genes exhibiting at least a two-fold change as compared to the control are shown in the table although another set of 13 genes belonging to the same network was also derived from the Ingenuity analysis with a cutoff of 1.2 for the fold change. For all of these genes, TCDD and $\alpha$-endosulfan exert their effects in the same direction.

The pathways related to cancer and control of the cell cycle, as well as the AhR signaling pathway, were up-regulated. The GTPase RAN (Ras-related nuclear protein) signaling pathway was also up-regulated. RAN is involved in cell differentiation and transformation, as it acts on the assembly of the mitotic apparatus and in nuclear protein import/export and its overexpression is linked to a poor prognosis in cancer [69].

There is no other published study on whole genome expression using TCDD and $\alpha$ endosulfan with which we can compare our results and thus the information provided here is novel. We, thus, compared our results following exposure of HepaRG to TCDD or $\alpha$ endosulfan alone with results published in the literature. None of the studies employ conditions that are identical to our work, but a similar study evaluated the effect of exposure of HepaRG cells to $10 \mathrm{nM}$ TCDD or $30 \mu \mathrm{M} 17 \beta$-estradiol for 12 or 48 hours [42] and two other analyses employed primary human hepatocytes exposed to several concentrations of TCDD for different times [63, 64]. Several of the up- and down-regulated gene sets derived from these studies were enriched in the most strongly up- and down-regulated genes in our 
own ranked list when analyzed by the gene set enrichment analysis algorithm (Figure S3). For the only study employing $17 \beta$-estradiol [42], the down-regulated gene sets for both the 12 and 48 hour treatments with $30 \mu \mathrm{M} 17 \beta$-estradiol and the up-regulated gene set for the 12 hour treatment were enriched in the down- and up-regulated genes of our ranked list for $\alpha$ endosulfan with FDRq (false discovery rate) $<1 \times 10^{-5}$ and FWER (family wise error rate according to Benjamini and Hochberg [67] $<1 \times 10^{-4}$. Rank rank hypergeometric overlap also identified statistically significant overlap between the expression signatures found by Jennen et al. [42] for $17 \beta$-estradiol (both 12 and 48 hour treatments) and our own for $\alpha$-endosulfan (see Figure S3 for representative GSEA curves and Rank Rank Hypergeometric heat maps). For TCDD, most enrichment was found (based on the normalized enrichment scores) for the up and down-regulated gene sets of Jennen et al. [42] following exposure of HepaRG to 10nM TCDD for 12 or 48 hours. Significant enrichment was also found for the up- and down-regulated sets of Forgacs et al. [64] following exposure of primary hepatocytes to 10nM TCDD for 12 and 48 hours as well as the up-regulated gene set for exposure for 24 hours. Less significant enrichment was found for the gene set of up-regulated genes of Carlson et al. [63] following exposure of primary hepatocytes to 10nM TCDD, although the FDRq was $<1 \times 10^{-5}$ and the FWER was $<1 \times 10^{-4}$ (data not shown). Finally, we compared the lists of genes that were differentially regulated by treatment with TCDD alone in our samples with those of a microarray study performed on primary mouse hepatocytes [55]. Although the lists of genes that were most strongly up- and down-regulated by TCDD in the mouse hepatocytes mapped among the most strongly up- and down-regulated genes in our ranked list, when analyzed by the Gene SetEnrichment Analysis algorithm (GSEA, $\mathrm{p}<0.001$; data not shown), the FDR and FWER values were not as significant as for the gene sets from the HepaRG cell line or the primary human hepatocytes. 
Taken together, the results attest to an overlap in the regulations of gene expression by estradiol and $\alpha$-endosulfan in HepaRG cells as well as to common effects of exposure to TCDD in the HepaRG cell line and primary human hepatocytes.

\section{Discussion}

Elucidation of the mechanisms by which mixtures of compounds, which act via different pathways or xenosensors, can affect cell function may be useful for further understanding how toxicants interact and how these interactions might affect toxicity. However, as concerns human hepatotoxicity, there is no one model system that is ideal for elucidating these mechanisms. Epidemiological studies may be incomplete as to exposure, may have small numbers of participants which limit the power of the statistical analyses for detection of effects, may have concomitant exposures to other counfouding factors that may have effects and, finally, may involve extrapolations over long periods of time that may lead to considerable errors in estimations of initial exposure. In vivo animal models are limited by the differences that exist between animals and humans and by the difficulty in extrapolating effects found in animals to humans $[70,71]$.

Primary cultures or permanent cell lines, in vitro, are not exposed to the local factors derived from the organ or to factors originating at a distance in the organism. Nevertheless, in vitro studies present advantages for studying cell type specific mechanisms and have been promoted by regulatory agencies as alternatives to animal studies $[71,72]$ and transcriptomics has proven useful in identifying pathways perturbed by toxicants [73]. However, species specific differences exist between animal and human primary hepatocyte cultures [63]. Further, human primary cultures exhibit variability due to differences in the donors with respect to genetics [74], demographics, disease and drug therapies [75-77] and this variability may be manifest following xenobiotic exposure [78]. Finally, there may also 
be differences in the response to toxicants between human primary hepatocytes and established human hepatic cell lines [79-81] or among established human hepatocyte cell lines $[42,82,83]$.

In this study, we have used a human liver-derived cell line, HepaRG, to provide novel information concerning the effects on hepatocyte function of a mixture of POPs that exert their effects via different xenosensors. TCDD, which binds to the AhR, and $\alpha$-endosulfan, which acts via the ER and/or PXR signalling pathways, were chosen because they both accumulate in the liver in animals and humans, they are suspected of having noncarcinogenic hepatic toxicity and there is knowledge of their effects individually (at least for TCDD) that may help to understand the effects of the mixture. The concentrations that were employed maximize the activation of the corresponding signalling pathways without leading to overt toxicity during the course of the experiment.

To our knowledge, this is the first genome-wide study in a human hepatic cell model of the effects of $\alpha$-endosulfan alone or in combination with TCDD thus providing novel information on the modulation of global gene expression by the ER and/or PXR xenosensors alone and in combination with the AhR. The results demonstrate that, for the most part, the effects of TCDD and $\alpha$-endosulfan on HepaRG hepatocytes are uncorrelated, which is consistent with these compounds exerting their effects by different mechanisms (pathways). However, it is also clear that the combined effects of $\alpha$-endosulfan and TCDD are greater than those of each POP alone. Thus, for concentrations at which TCDD or $\alpha$-endosulfan, individually, do not alter gene expression significantly, the mixture does produce a significant modification in the expression of 100 genes, although it should be emphasized that no conclusions can be made regarding the additivity or synergy of effects given that only a single concentration of each pollutant was studied. Further, although inspection of Table S2 reveals that many genes appear to exhibit some modulation in the level of their expression 
after treatment with one pollutant, these changes are not significant given the stringency of the statistical analysis and the low level of expression of those genes in many cases. This may illustrate the delicacy of establishing zero-effect levels.

We also found evidence for what appears to be selective inhibitory crosstalk within the AhR and ER/PXR pathways. TCDD, in the mixture, inhibited the effects of $\alpha$-endosulfan on the expression of 10 genes and $\alpha$-endosulfan inhibited the effects of TCDD on 21 genes (Table 1). Serine dehydratase, the expression of which is affected by both TCDD and $\alpha$ endosulfan, but not the mixture, may be added to these ensembles although the mechanisms may not be the same. Several mechanisms for inhibitory AhR-ER $\alpha$ cross-talk, which may be gene/response and cell-context dependent, have been derived from the study of various nonhepatic models [84-86]. Our observations would appear to be novel for a human hepaticderived cell line and the genes identified, if validated, might be useful targets to further understand these negative mechanisms of regulation in the liver.

Our investigation further revealed that the response to the mixture of these endocrine disruptors involves both increases and decreases in the expression of many genes which belong to several pathways. However, the drastic down-regulation of genes involved in several metabolic pathways, such as lipid metabolism, which is the top network for downregulated genes, is particularly striking. mRNA expression is almost abolished for some of the genes by the mixture. Indeed, some genes, which were not identified as targets after treatment by a single pollutant because the fold change in their expression was below the cut off, are identified following treatment by the combination of pollutants as a result of a significant change in their expression.

Among the genes belonging to the lipid metabolism network (See Table S4) is ADH4, a member of the alcohol dehydrogenase family, which is organized as a cluster on chromosome 4 (ADH1A, B, C, ADH4 and ADH6). Interestingly, the drastic down-regulation 
of the expression of several of these ADHs has been linked to increased aggressiveness and a lower survival rate in breast, liver or lung cancer $[87,88]$. The expression of these genes, as well as those of RDH16 (retinol dehydrogenase) and CYP2E1, all of which metabolize ethanol and/or retinoids, was decreased 70 to $80 \%$ in HepaRG cells exposed to both pollutants. These changes in the level of mRNA were paralleled by changes in the amount of protein as shown for ADH1. Moreover, we observed a similar type of regulation using lower concentrations of pollutants and a longer time of exposure.

The members of the alcohol dehydrogenase family metabolize a wide variety of substrates such as ethanol and vitamin A, various aliphatic alcohols and lipid peroxydation products. Several studies have shown clearly that dioxins, through the AhR, disturb retinoid homeostasis, in particular by decreasing hepatic vitamin A and by increasing oxidation of the retinoids [89]. A few studies suggest a role for other pollutants, such as pesticides, in the deregulation of retinoid homeostasis [90].

The drastic down-regulation, up to $80 \%$, of the expression of the alcohol dehydrogenase gene family by the combination of dioxin and $\alpha$-endosulfan could thus exacerbate the modulation of vitamin A content and retinoic acid production induced by a single pollutant in the liver, thus further affecting signalling through the RAR-RXR pathway. In fact, hepatic vitamin A depletion in rodent models after treatment with TCDD has been linked to CYP1A1 induction and increased metabolism of this nutrient [91]. It has been suggested that alteration of retinoid metabolism could play a role in the wasting syndrome associated with dioxin exposure [92]. Our results also suggest that the almost complete inhibition of the expression of several enzymes involved in retinoid and/or alcohol metabolism by the combination of TCDD and $\alpha$-endosulfan may profoundly alter the homeostasis of vitamin A and impair the protective role of retinoic acids in cancer, aging or immuno-stimulation. 
The combination of pollutants also inhibited the genes for several enzymes which belong to the FXR/RXR axis, which plays a role in bile acid signalling. The expression of a key enzyme involved in bile acid biosynthesis from cholesterol (CYP7A1) was downregulated by $80 \%$, following treatment with the mixture of POPs (Table S4). TCDD also decreased CYP7A1 expression in a rat liver model [92]. The expression of the canalicular half-transporters $\mathrm{ABCG} 5 / \mathrm{G} 8$, which associate at the plasma membrane to control the excretion of excess cholesterol from the liver, was inhibited by $70 \%$ following treatment with the combination of pollutants (Table S4). Thus, the down-regulation of these genes may contribute to increased cellular cholesterol and fatty liver disease [93] and, along with other factors, to the development of the metabolic syndrome [94]. The treatment with the mixture also resulted in a $90 \%$ decrease in expression of the gene for the liver catalytic subunit of glucose 6 phosphatase (G6PC). G6PC is the final enzyme in gluconeogenesis and glycogenolysis which provides energy and controls the serum glucose level in the blood during fasting. These results are in line with the $50 \%$ decrease in the expression of G6PC that is observed in both the human hepatoma cell line HuH7 treated with the PXR agonist rifampicin [95] and in chick embryo hepatocytes treated with TCDD [96]. Several epidemiological studies indicate an association between obesity and the metabolic syndrome and the concentration of POPs in serum [4, 6, 97] and our results concerning the effects on hepatocyte gene expression may be consistent with a role of POPs in this syndrome. Finally, exposure to numerous pollutants is often associated with an increase in cancer [98] and the up-regulation of the genes involved in AhR signalling, the molecular mechanisms of cancer and cell cycle checkpoint control that we observe is consistent with these studies.

In the future, comparison of acute and "chronic" exposures to lower pollutant concentrations will be important. The HepaRG cell line is a human model of choice for studying such sub-chronic treatments since the differentiated cells stably express (for two 
weeks at least) several CYPs and receptors for xenobiotics [39]. Our results obtained with an 8 -day treatment with low doses of TCDD and $\alpha$-endosulfan indicate that low doses over longer periods of time can lead to changes in gene expression similar to those obtained with an acute treatment at higher concentrations of POPs.

Epidemiological studies have associated chronic exposure to low levels of POPs with metabolic disorders such as insulin resistance or disruption of lipid metabolism [97, 99, 100]. Indeed, there are major concerns about the fact that living organisms are exposed to complex mixtures of POPs throughout their lifespan and that the effects of combinations are not well characterized. Our transcriptomic study was thus designed to pinpoint which genes had their expression severely dysregulated by the combination used. Our findings emphasize that deleterious hepatocellular effects may be more pronounced with a mixture of POPs which act through different signalling pathways as compared to each POP alone. We are currently investigating the effects of the mixture on a number of metabolic pathways down-regulated in the study and deciphering which receptors are involved in these effects.

With respect to the effects of TCDD, although manifestations of hepatotoxicity (hepatocellular tumors, cytoplasmic vacuolization, multinucleate hepatocytes, inflammation, steatosis, necrosis) have been noted [101-103] in several laboratory animals (mouse, rat, chicken, guinea pig, rabbit, zebra fish), the United States Environmental Protection Agency in its reanalysis of key issues related to dioxin toxicity [24] noted that "hepatic effects were evident in virtually all rodent studies that looked for them and are often severe, although not evident in humans". Further, it is not clear whether toxicant-associated steatohepatitis develops in humans exposed to TCDD [104] and although there appears to be an association between dioxin and type 2 diabetes a causal link is not necessarily implied [5, 10, 105, 106]. Continued investigation in a variety of model systems clearly seems warranted to further elucidate the mechanisms of action of these pollutants in humans. 
In conclusion, this study provides novel information on the increased effects on global gene expression of a mixture of environmental POPs, as compared to each one individually, in a human liver-derived model and, in particular, on the down-regulation of genes involved in metabolic pathways. It also demonstrates that in spite of their effects being largely uncorrelated, TCDD and $\alpha$-endosulfan act together to affect the expression of a significant number of genes by several different mechanisms. Finally, the study provides novel information concerning the usefulness of the HepaRG cell line as a model system for studying human hepatocyte specific xenobiotic effects. 


\section{Acknowledgments}

We thank Mrs D. Glaise for her help with the HepaRG cell culture, Dr L. Aggerbeck and Dr E. Blanc for critical reading of the manuscript and F. Dumont for help with the bioinformatics.

Financial support: This work was supported by ANR (Agence Nationale pour la Recherche) [06SETS26, Oncopop], Association de la Recherche sur le Cancer [ARC-3927], INSERM (Institut National de la Santé et de la Recherche Médicale), Université Paris Descartes, MESR (Ministère de l'Enseignement Supérieur et de la Recherche) (doctoral fellowships, Ariane Ambolet-Camoit, Alix Leblanc), and the European Union's Seventh Programme for research, technological development and demonstration (HEALS project, grant agreement Number. 603946). 


\section{References}

1. White SS, Birnbaum LS (2009) An overview of the effects of dioxins and dioxin-like compounds on vertebrates, as documented in human and ecological epidemiology. $\mathrm{J}$ Environ Sci Health C Environ Carcinog Ecotoxicol Rev 27:197-211.

2. Rochester JR (2013) Bisphenol A and human health: a review of the literature. Reprod Toxicol 42:132-155.

3. Alavanja MC, Hoppin JA, Kamel F (2004) Health effects of chronic pesticide exposure: cancer and neurotoxicity. Annu Rev Public Health 25:155-197.

4. Lee DH, Steffes MW, Sjodin A, Jones RS, Needham LL, et al. (2011) Low dose organochlorine pesticides and polychlorinated biphenyls predict obesity, dyslipidemia, and insulin resistance among people free of diabetes. PLoS One 6:e15977.

5. Lee DH, Porta M, Jacobs DR Jr, Vandenberg LN (2014) Chlorinated persistent organic pollutants, obesity, and type 2 diabetes. Endocr Rev 35:557-601.

6. Lim S, Cho YM, Park KS, Lee HK (2010) Persistent organic pollutants, mitochondrial dysfunction, and metabolic syndrome. Ann N Y Acad Sci 1201:166176.

7. Thayer K, Heindel JJ, Bucher JR, Gallo MA (2012) Role of environmental chemicals in diabetes and obesity: A National Toxicology Program Workshop Review. Environ Health Perspect 120:779-789.

8. Kamel F (2013) Epidemiology. Paths from pesticides to Parkinson's. Science 341:722-723.

9. Warner, M, Mocarelli, P, Brambilla, P, Wesselink, A, Samuels, S, et al. (2013) Diabetes, metabolic syndrome and obesity in relation to serum dioxin concentrations : The Seveso Women's Health Study. Environ Health Perspect 121:906-911.

10. Magliano DJ, Loh VH, Harding JL, Botton J, Shaw JE (2014) Persistent organic pollutants and diabetes: a review of the epidemiological evidence. Diabetes Metab 40:1-14.

11. Loeffler IK, Peterson RE (1999) Interactive effects of TCDD and p,p'-DDE on male reproductive tract development in in utero and lactationally exposed rats. Toxicol Appl Pharmacol 154:28-39.

12. Coumoul X, Diry M, Robillot C, Barouki R (2001) Differential regulation of cytochrome P450 1A1 and 1B1 by a combination of dioxin and pesticides in the breast tumor cell line MCF-7. Cancer Res 61:3942-3948.

13. Perobelli JE, Martinez MF, da Silva Franchi CA, Fernandez CD, de Camargo JL, et al. (2010) Decreased sperm motility in rats orally exposed to single or mixed pesticides. J Toxicol Environ Health A73:991-1002.

14. Rana I, Shivanandappa $T$ (2010) Mechanism of potentiation of endosulfan cytotoxicity by thiram in Ehrlich ascites tumor cells. Toxicol In Vitro 24:40-44.

15. Kopec AK, D'Souza ML, Mets BD, Burgoon LD, Reese SE, et al. (2011) Nonadditive hepatic gene expression elicited by 2,3,7,8-tetrachlorodibenzo-p-dioxin (TCDD) and 2,2',4,4',5,5'-hexachlorobiphenyl (PCB153) co-treatment in C57BL/6 mice. Toxicol Appl Pharmacol 256:154-167.

16. Evans RM, Scholze M, Kortenkamp A (2012) Additive mixture effects of estrogenic chemicals in human cell-based assays can be influenced by inclusion of chemicals with differing effect profiles. PLoS One7:e43606. 
17. Nawaz A, Razpotnik A, Rouimi P, de Sousa G, Cravedi JP, et al. (2014) Cellular impact of combinations of endosulfan, atrazine, and chlorpyrifos on human primary hepatocytes and HepaRG cells after short and chronic exposures. Cell Biol Toxicol 30:17-29.

18. Savary CC, Josse R, Guillet F, Bruyere A, Robin MA, et al. (2014) Interactions of Endosulfan and Methoxychlor Involving CYP3A4 and CYP2B6 in Human HepaRG Cells. Drug Metab Dispos 42:1235-1240.

19. Van den Dungen DW, Rijk JCW, Kampman E, Steegenga WT, Murk AJ (2015) Steroid hormone related effects of marine persistent organic pollutants in human H295R adrenocortical carcinoma cells. Toxicol In Vitro 29:769-778.

20 Kortenkamp A (2007) Ten years of mixing cocktails: a review of combination effects of endocrine-disrupting chemicals. Environ Health Perspect 115 Suppl 1:98-105.

21. Kortenkamp A, Faust M, Scholze M, Backhaus T (2007) Low-level exposure to multiple chemicals: reason for human health concerns? Environ Health Perspect 115 Suppl 1:106-114.

22. U.S. EPA Environmental Protection Agency (2002) Environmental Fate and Ecological Risk Assessment for the Reregistration Eligibility Decision on Endosulfan (Thiodan). DP Barcode D238673; U.S. Environmental Protection Agency, Office of Pesticide Programs, Environmental Fate and Effects Division, Washington, DC; 224 pp.

23. U.S. EPA Environmental Protection Agency (2007) RED (Re-registration Eligibility Decision), document: endosulfan updated risk assessments, notice of availability, and solicitation of usage information. Federal Register U.S. Environmental Protection Agency; 64624-6; Docket: EPA-HQ-OPP-2002-0262.

24. U. S. EPA Environmental Protection Agency (2012) EPA's Reanalysis of Key Issues Related to Dioxin Toxicity and Response to NAS Comments, Volume 1 (CAS No. 1746-01-6) EPA/600/R-10/038F U.S. Environmental Protection Agency, Washington, D.C.

25. Agency for Toxic Substances and Disease Registry (ATSDR) (2013) Toxicological profile for endosulfan. (Draft for Public Comment) Atlanta, GA: U.S. Department of Health and Human Services, Public Health Service.

26. Coumoul X, Diry M, Barouki R (2002) PXR-dependent induction of human CYP3A4 gene expression by organochlorine pesticides. Biochem Pharmacol 64:1513-1519.

27. Casabar RC, Das PC, Dekrey GK, Gardiner CS, Cao Y, et al. (2010) Endosulfan induces CYP2B6 and CYP3A4 by activating the pregnane $\mathrm{X}$ receptor. Toxicol Appl Pharmacol 245:335-343.

28. Lemaire G, Mnif W, Mauvais P, Balaguer P, Rahmani R (2006) Activation of alphaand beta-estrogen receptors by persistent pesticides in reporter cell lines. Life Sci 79:1160-1169.

29. Caride A, Lafuente A, Cabaleiro T (2010) Endosulfan effects on pituitary hormone and both nitrosative and oxidative stress in pubertal male rats. Toxicol Lett 197:106112.

30. Mrema EJ, Rubino FM, Brambilla G, Moretto A, Tsatsakis AM, et al. (2013) Persistent organochlorinated pesticides and mechanisms of their toxicity. Toxicology 307:74-88.

31. Kumar GK, Klein JB (1985) Analysis of expression and posttranslational modification of proteins during hypoxia. J Appl Physio 196:1178-1186; discussion 1170-1172. 
32. Yoshida R, Ogawa Y (2000) Oxidative stress induced by 2,3,7,8-tetrachlorodibenzop-dioxin: an application of oxidative stress markers to cancer risk assessment of dioxins. Ind Health 38:5-14.

33. Zappulla D (2008) Environmental stress, erythrocyte dysfunctions, inflammation, and the metabolic syndrome: adaptations to CO2 increases? J Cardiometab Syndr 3:30-34.

34. Lang F, Gulbins E, Lang PA, Zappulla D, Föller M (2010) Ceramide in suicidal death of erythrocytes. Cell Physiol Biochem 26:21-28.

35. Khan, KH (2012) Impact of endosulfan on living beings. International Journal of Biosciences 2:9-17.

36. Trayhurn P (2014) Hypoxia and adipocyte physiology: implications for adipose tissue dysfunction in obesity. Annu Rev Nutr 34:207-236.

37. Moon JM, Chun BJ (2009) Acute endosulfan poisoning: a retrospective study. Hum Exp Toxicol 28:309-316.

38. Guillouzo A, Corlu A, Aninat C, Glaise D, Morel F, et al. (2007) The human hepatoma HepaRG cells: a highly differentiated model for studies of liver metabolism and toxicity of xenobiotics. Chem Biol Interact 168:66-73.

39. Antherieu S, Chesne C, Li R, Camus S, Lahoz A, et al. (2010) Stable expression, activity, and inducibility of cytochromes P450 in differentiated HepaRG cells. Drug Metab Dispos 38:516-525.

40. Hart SN, Li Y, Nakamoto K, Subileau EA, Steen D, et al. (2010) A comparison of whole genome gene expression profiles of HepaRG cells and HepG2 cells to primary human hepatocytes and human liver tissues. Drug Metab Dispos 38:988-994.

41. Xu JJ, Diaz D, O'Brien PJ (2004) Applications of cytotoxicity assays and pre-lethal mechanistic assays for assessment of human hepatotoxicity potential. Chem Biol Interact 150:115-128.

42. Jennen DG, Magkoufopoulou C, Ketelslegers HB, van Herwijnen MH, Kleinjans JC, et al. (2010) Comparison of HepG2 and HepaRG by whole-genome gene expression analysis for the purpose of chemical hazard identification. Toxicol Sci 115:66-79.

43. Gerets HH, Tilmant K, Gerin B, Chanteux H, Depelchin BO, et al. (2012) Characterization of primary human hepatocytes, HepG2 cells, and HepaRG cells at the mRNA level and CYP activity in response to inducers and their predictivity for the detection of human hepatotoxins. Cell Biol Toxicol 28:69-87.

44. Kanebratt KP, Andersson TB. (2008) Evaluation of HepaRG cells as an in-vitro model for human drug metabolism studies. Drug Metab Dispos 36:1444-1452.

45. Lübberstedt M, Müller-Vieira U, Mayer M, Biemel KM, Knöspel F, et al. (2011) HepaRG human hepatic cell line utility as a surrogate for primary human hepatocytesin drug metabolism assessment in vitro. J Pharmacol Toxicol Methods 63:59-68.

46. Kotani N, Maeda K, Debori Y, Camus S, Li R, et al. (2012) Expression and transport function of drug uptake transporters in differentiated HepaRG cells. Mol Pharm 9:3434-3441.

47. Rogue A, Lambert C, Spire C, Claude N, Guillouzo A (2012) Interindividual variability in gene expression profiles in human hepatocytes and comparison with HepaRG cells. Drug Metab Dispos 40:151-158.

48. Samanez CH, Caron S, Briand O, Dehondt H, Duplan I, et al. (2012) The human hepatocyte cell lines IHH and HepaRG: models to study glucose, lipid and lipoprotein metabolism. Arch Physiol Biochem 118:102-111.

49. Guillouzo A, Morel F, Fardel O, Meunier B (1993) Use of human hepatocyte cultures for drug metabolism studies. Toxicology 82:209-219. 
50. Madan A, Graham RA, Carroll KM, Mudra DR, Burton LA, et al. (2003) Effects of prototypical microsomal enzyme inducers on cytochrome P450 expression in cultured human hepatocytes. Drug Metab Dispos 31:421-431.

51. Lambert CB, Spire C, Claude N, Guillouzo A (2009) Dose- and time-dependent effects of phenobarbital on gene expression profiling in human hepatoma HepaRG cells.Toxicol Appl Pharmacol 234:345-360.

52. Godoy P, Hengstler JG, Ilkavets I, Meyer C, Bachmann A, et al. (2009) Extracellular matrix modulates sensitivity of hepatocytes to fibroblastoid dedifferentiation and transforming growth factor beta-induced apoptosis. Hepatology 49:2031-2043.

53. Gripon P, Rumin S, Urban S, Le Seyec J, Glaise D, et al. (2002) Infection of a human hepatoma cell line by hepatitis B virus. Proc Natl Acad Sci USA 99:15655-15660.

54. Aninat C, Piton A, Glaise D, Le Charpentier T, Langouet S, et al. (2006) Expression of cytochromes $\mathrm{P} 450$, conjugating enzymes and nuclear receptors in human hepatoma HepaRG cells. Drug Metab Dispos 34:75-83.

55. Bui LC, Tomkiewicz C, Chevallier A, Pierre S, Bats AS, et al. (2009) Nedd9/Hef1/Cas-L mediates the effects of environmental pollutants on cell migration and plasticity. Oncogene 28:3642-3651.

56. Imbeaud S, Graudens E, Boulanger V, Barlet X, Zaborski P, et al. (2005) Towards standardization of RNA quality assessment using user-independent classifiers of microcapillary electrophoresis traces. Nucleic Acids Res 33:e56.

57. Cole SW, Galic Z, Zack JA (2003) Controlling false-negative errors in microarray differential expression analysis: a PRIM approach. Bioinformatics 19:1808-1816.

58. Garcia-Ortiz JE, Pelosi E, Omari S, Nedorezov T, Piao Y, et al. (2009) Foxl2 functions in sex determination and histogenesis throughout mouse ovary development. BMC Dev Biol 9:36.

59. Reich M, Liefeld T, Gould J, Lerner J, Tamayo P, et al. (2006) GenePattern 2.0. Nature Genetics 38:500-501.

60. Mootha VK, Lindgren CM, Eriksson KF, Subramanian A, Sihag S, et al. (2003) PGC1alpha-responsive genes involved in oxidative phosphorylation are coordinately downregulated in human diabetes. Nat Genet 34:267-273.

61. Subramanian A, Tamayo P, Mootha VK, Mukherjee S, Ebert BL, et al. (2005) Gene set enrichment analysis: a knowledge-based approach for interpreting genome-wide expression profiles. Proc Natl Acad Sci U S A 102:15545-15550.

62. Plaisier SB, Taschereau R, Wong JA, Graeber TG (2010) Rank-rank hypergeometric overlap: identification of statistically significant overlap between gene-expression signatures. Nucleic Acids Res 38:e169.

63. Carlson EA, McCulloch C, Koganti A, Goodwin SB, Sutter TR, et al. (2009) Divergent transcriptomic responses to aryl hydrocarbon receptor agonists between rat and human primary hepatocytes. Toxicol Sci 112:257-272.

64. Forgacs AL, Dere E, Angrish MM, Zacharewski TR (2013) Comparative Analysis of Temporal and Dose-Dependent TCDD-Elicited Gene Expression in Human, Mouse, and Rat Primary Hepatocytes. Toxicol Sci 133:54-66.

65. Flaveny CA, Murray IA, Perdew GH (2010) Differential gene regulation by the human and mouse aryl hydrocarbon receptor. Toxicol Sci 114:217-225.

66. Beaton, AE, Tukey, JW (1974) The fitting of power series, meaning polynomials, illustrated on band-spectroscopic data. Technometrics 16:147-185.

67. Benjamini, Y, Hochberg, Y (1995) Controlling the false discovery rate: a practical and powerful approach to multiple testing. Journal of the Royal Statistical Society, Series B (Methodological) 57:289-300. 
68. Micallef L, Rodgers P (2014) eulerAPE: Drawing area-proportional 3-Venn diagrams using ellipses. PLoS One 9:e101717.

69. Ly TK, Wang J, Pereira R, Rojas KS, Peng X, et al. (2010) Activation of the Ran GTPase is subject to growth factor regulation and can give rise to cellular transformation. J Biol Chem 285:5815-5826.

70. Seok J, Warren HS, Cuenca AG, Mindrinos MN, Baker HV, et al. (2013) Inflammation and Host Response to Injury, Large Scale Collaborative Research Program : Genomic responses in mouse models poorly mimic human inflammatory diseases. Proc Natl Acad Sci U S A 110:3507-3512.

71. National Research Council. (2007). Toxicity Testing in the 21st Century: A Vision and a Strategy. National Research Council Committee on Toxicity Testing and Assessment of Environmental Agents, The National Academies Press, Washington, DC. Available at: http://www.nap.edu/catalog.php?record_id1/411970.

72. Organization for economic cooperation and development. (2011) Report of the workshop on using mechanistic information in forming chemical categories (no. 138, series on testing and assessment). OECD, Crystal City.

73. Jennings P, Limonciel A, Felice L, Leonard MO (2013) An overview of transcriptional regulation in response to toxicological insult. Arch Toxicol 87:49-72.

74. Lamba JK, Lin YS, Schuetz EG, Thummel KE (2002) Genetic contribution to variable human CYP3A-mediated metabolism. Adv Drug Deliv Rev 54:1271-1294.

75. Slatter JG, Templeton IE, Castle JC, Kulkarni A, Rushmore TH, et al. (2006) Compendium of gene expression profiles comprising a baseline model of the human liver drug metabolism transcriptome. Xenobiotica 36:938-962.

76. Villeneuve JP, Pichette V (2004) Cytochrome P450 and liver diseases. Curr Drug Metab 5:273-282.

77. Yang L, Price ET, Chang CW, Li Y, Huang Y, et al. (2013) Gene expression variability in human hepatic drug metabolizing enzymes and transporters. PLoS One 8:e60368.

78. Goyak KM, Johnson MC, Strom SC, Omiecinski CJ (2008) Expression profiling of interindividual variability following xenobiotic exposures in primary human hepatocyte cultures. Toxicol Appl Pharmacol 231:216-224.

79. Guo L, Dial S, Shi L, Branham W, Liu J, et al. (2011) Similarities and differences in the expression of drug-metabolizing enzymes between human hepatic cell lines and primary human hepatocytes. Drug Metab Dispos 39:528-538.

80. Sjogren AK, Liljevald M, Glinghammar B, Sagemark J, Li XQ, et al. (2014) Critical differences in toxicity mechanisms in induced pluripotent stem cell-derived hepatocytes, hepatic cell lines and primary hepatocytes. Arch Toxicol 88:1427-1437.

81. Vrba J, Havlikova M, Gerhardova D, Ulrichova J (2014) Palmatine activates AhR and upregulates CYP1A activity in HepG2 cells but not in human hepatocytes. Toxicol In Vitro 28:693-699.

82. Kim S, Dere E, Burgoon LD, Chang CC, Zacharewski TR (2009) Comparative analysis of AhR-mediated TCDD-elicited gene expression in human liver adult stem cells.Toxicol Sci 112:229-244.

83. Kim WK, In YJ, Kim JH, Cho HJ, Kim JH, et al. (2006) Quantitative relationship of dioxin-responsive gene expression to dioxin response element in Hep3B and HepG2 human hepatocarcinoma cell lines. Toxicol Lett 165:174-181.

84. Safe S, Wormke M (2003) Inhibitory aryl hydrocarbon receptor-estrogen receptor alpha cross-talk and mechanisms of action. Chem Res Toxicol 16:807-816.

85. Swedenborg E, Pongratz I (2010) AhR and ARNT modulate ER signaling. Toxicology 268:132-138. 
86. Marques M, Laflamme L, Gaudreau L (2013) Estrogen receptor alpha can selectively repress dioxin receptor-mediated gene expression by targeting DNA methylation. Nucleic Acids Res 41:8094-8102.

87. Mutka SC, Green LH, Verderber EL, Richards JP, Looker DL, et al. (2012) ADH IB expression, but not ADH III, is decreased in human lung cancer. PLoS One 7:e52995.

88. Wei RR, Zhang MY, Rao HL, Pu HY, Zhang HZ, et al. (2012) Identification of ADH4 as a novel and potential prognostic marker in hepatocellular carcinoma. Med Oncol 29:2737-2743.

89. Nilsson CB, Hakansson H (2002) The retinoid signaling system-a target in dioxin toxicity. Crit Rev Toxicol 32:211-232.

90. Novak J, Benisek M, Hilscherova K (2008) Disruption of retinoid transport, metabolism and signaling by environmental pollutants. Environ Int 34:898-913.

91. Fletcher N, Hanberg A, Hakansson H (2001) Hepatic vitamin a depletion is a sensitive marker of 2,3,7,8-tetrachlorodibenzo-p-dioxin (TCDD) exposure in four rodent species. Toxicol Sci 62:166-175.

92. Fletcher N, Wahlstrom D, Lundberg R, Nilsson CB, Nilsson KC, et al. (2005) 2,3,7,8Tetrachlorodibenzo-p-dioxin (TCDD) alters the mRNA expression of critical genes associated with cholesterol metabolism, bile acid biosynthesis, and bile transport in rat liver: a microarray study. Toxicol Appl Pharmacol 207:1-24.

93. Su K, Sabeva NS, Liu J, Wang Y, Bhatnagar S et al. (2012) The ABCG5 ABCG8 sterol transporter opposes the development of fatty liver and loss of glycemic control independently of phytosterol accumulation. J Biol Chem 287:28564-28575.

94 Lefebvre P, Cariou B, Lien F, Kuipers F, Staels B (2009) Role of bile acids and bile acid receptors in metabolic regulation. Physiol Rev 89:147-191.

95. Kodama S, Moore R, Yamamoto Y, Negishi M (2007) Human nuclear pregnane X receptor cross-talk with CREB to repress cAMP activation of the glucose-6phosphatase gene. Biochem J 407:373-381.

96. Diani-Moore S, Ram P, Li X, Mondal P, Youn DY, et al. (2010) Identification of the aryl hydrocarbon receptor target gene TiPARP as a mediator of suppression of hepatic gluconeogenesis by 2,3,7,8-tetrachlorodibenzo-p-dioxin and of nicotinamide as a corrective agent for this effect. J Biol Chem 285:38801-38810.

97. Silverstone AE, Rosenbaum PF, Weinstock RS, Bartell SM, Foushee HR, et al. (2012) Polychlorinated biphenyl (PCB) exposure and diabetes: results from the Anniston Community Health Survey. Environ Health Perspect 120:727-732.

98. Clapp RW, Jacobs MM, Loechler EL (2008) Environmental and occupational causes of cancer: new evidence 2005-2007. Rev Environ Health 23:1-37.

99. Consonni D, Pesatori AC, Zocchetti C, Sindaco R, D'Oro LC, et al. (2008) Mortality in a population exposed to dioxin after the Seveso, Italy, accident in 1976: 25 years of follow-up. Am J Epidemiol 167:847-858.

100. Inadera H. (2013) Developmental origins of obesity and type 2 diabetes molecular aspects and role of chemicals. Environ Health Prev Med 18:185-197.

101. Mann, PC (1997) Selected lesions of dioxin in laboratory rodents. Toxicol Pathol 25: 72-79.

102. El-Sabeawy F, Enan E, Lasley B (2001) Biochemical and toxic effects of 2,3,7,8tetrachlorodibenzo-p-dioxin in immature male and female chickens. Comp Biochem Physiol C Toxicol Pharmacol 129:317-327.

103. Zodrow JM, Stegeman JJ, Tanguay RL (2004) Histological analysis of acute toxicity of 2,3,7,8-tetrachlorodibenzo-p-dioxin (TCDD) in zebrafish. Aquat Toxicol 66:25-38.

104. Wahlang B, Beier JI, Clair HB, Bellis-Jones HJ, Falkner KC, et al. (2013) Toxicantassociated steatohepatitis. Toxicol Pathol 41:343-360. 
105. Taylor KW, Novak RF, Anderson HA, Birnbaum LS, Blystone C, et al. (2013) Evaluation of the association between persistent organic pollutants (POPs) and diabetes in epidemiological studies: a national toxicology program workshop review. Environ Health Perspect 121:774-783.

106. De Tata, V (2014) Association of dioxin and other persistent organic pollutants (POPs) with diabetes: epidemiological evidence and new mechanisms of beta cell dysfunction. Int J Mol Sci 15: 7787-7811. 


\section{Figure legends}

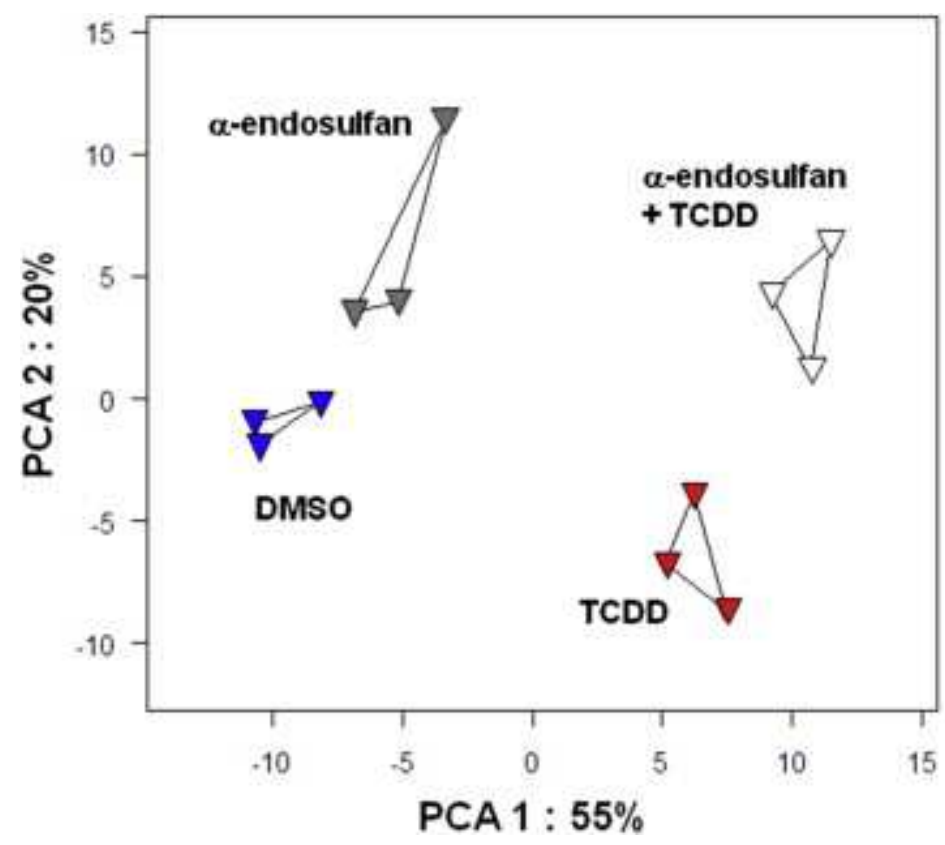

Figure 1. Principal Component Analysis (PCA) of the top 1,000 most variable genes. The expression profiles discriminate the experimental conditions. The total variance explained by either component is given in \%. Triangles represent the samples and the lines connect the samples from the same experimental condition: DMSO (blue), $\alpha$-endosulfan (grey), TCDD (red), mixture of TCDD and $\alpha$-endosulfan (white). 


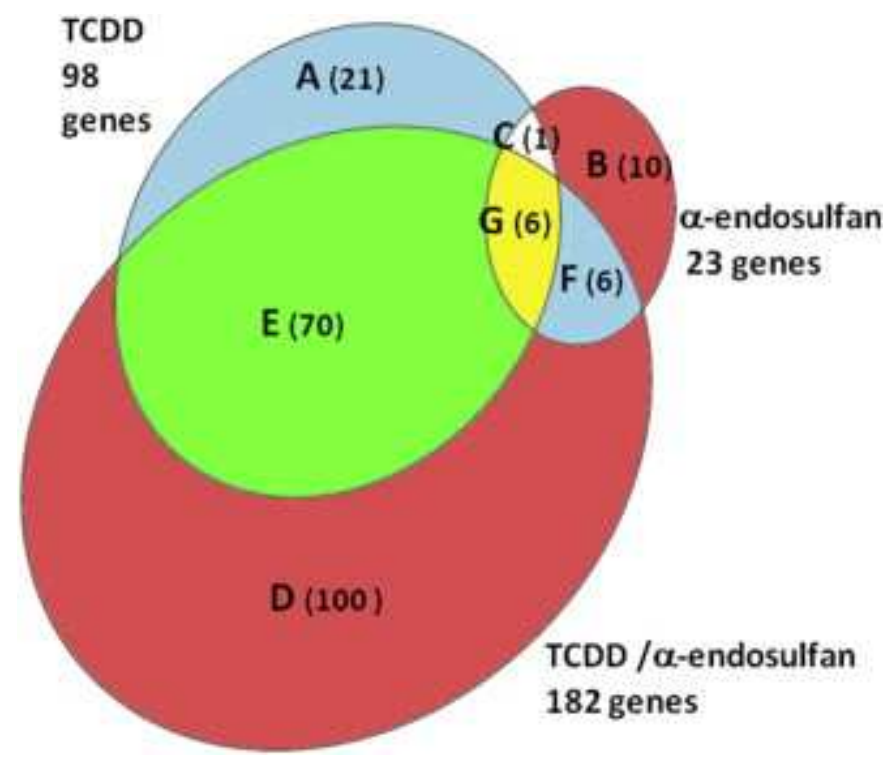

Figure 2. Exact-area proportional Euler diagram for the genes that are differentially regulated by the POP treatments. The total numbers of genes up- and down-regulated (pvalue $\leq 0.05,>2$-fold change, absolute value) following exposure of differentiated HepaRG cells to $25 \mathrm{nM}$ TCDD, $10 \mu \mathrm{M} \alpha$-endosulfan or their combination for $30 \mathrm{H}$ are shown. 


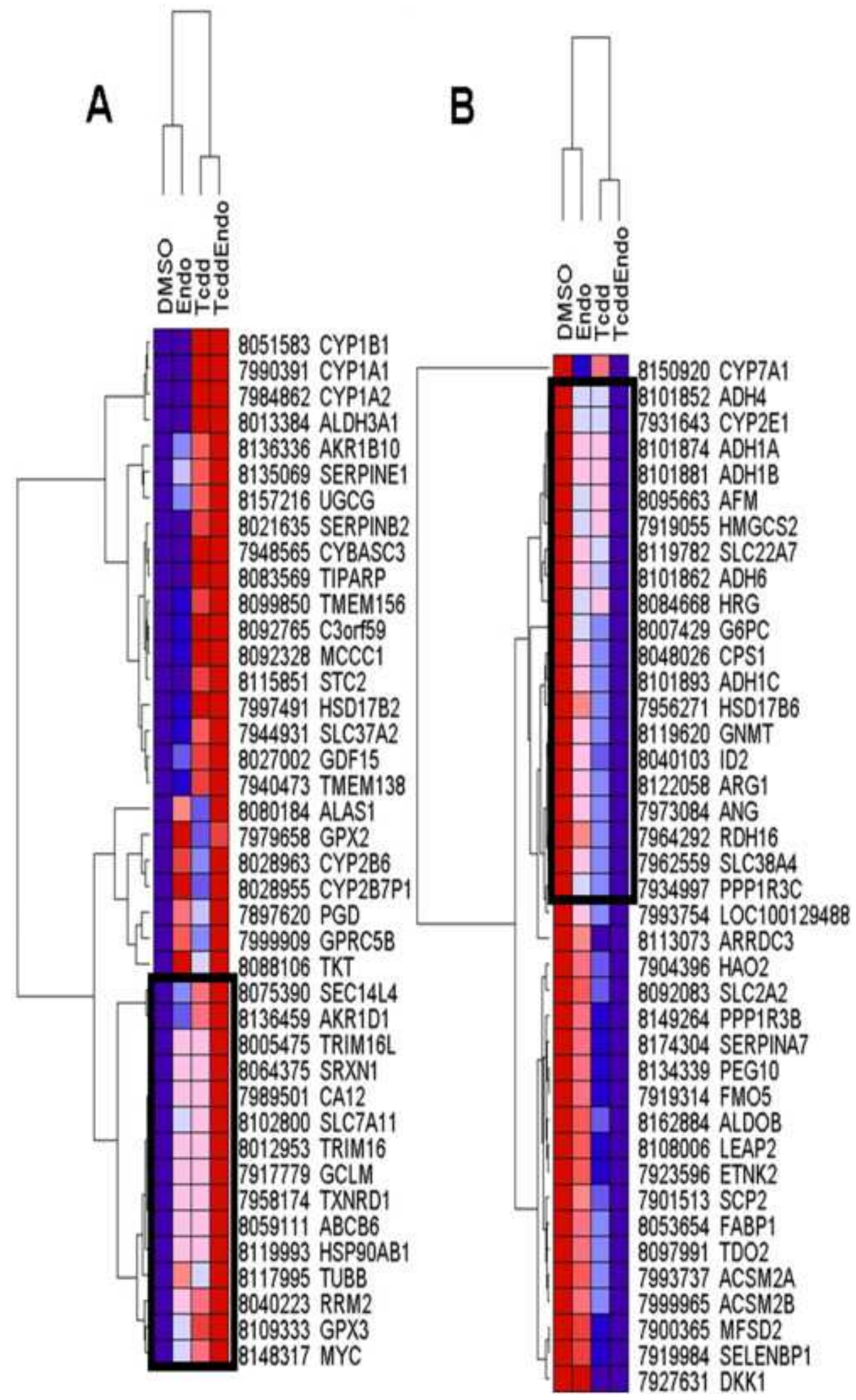

Figure 3. Hierarchical clustering analysis of 80 genes showing the greatest changes compared to vehicle $(\mathbf{0 . 1 5 \%}$ DMSO). Increased $(\mathrm{N}=40)$ and decreased $(\mathrm{N}=40)$ levels of 
expression are shown in the left (A) and right (B) panels, respectively. The rows represent the genes. The columns represent the enrichment scores for each gene in the treatments. The black lined boxes indicate gene clusters that show strongly increased up-regulation (A) or down-regulation (B) after treatment of cells with the mixture as compared to the individual POPs. Red and blue colors indicate up- and down-regulation, respectively. 

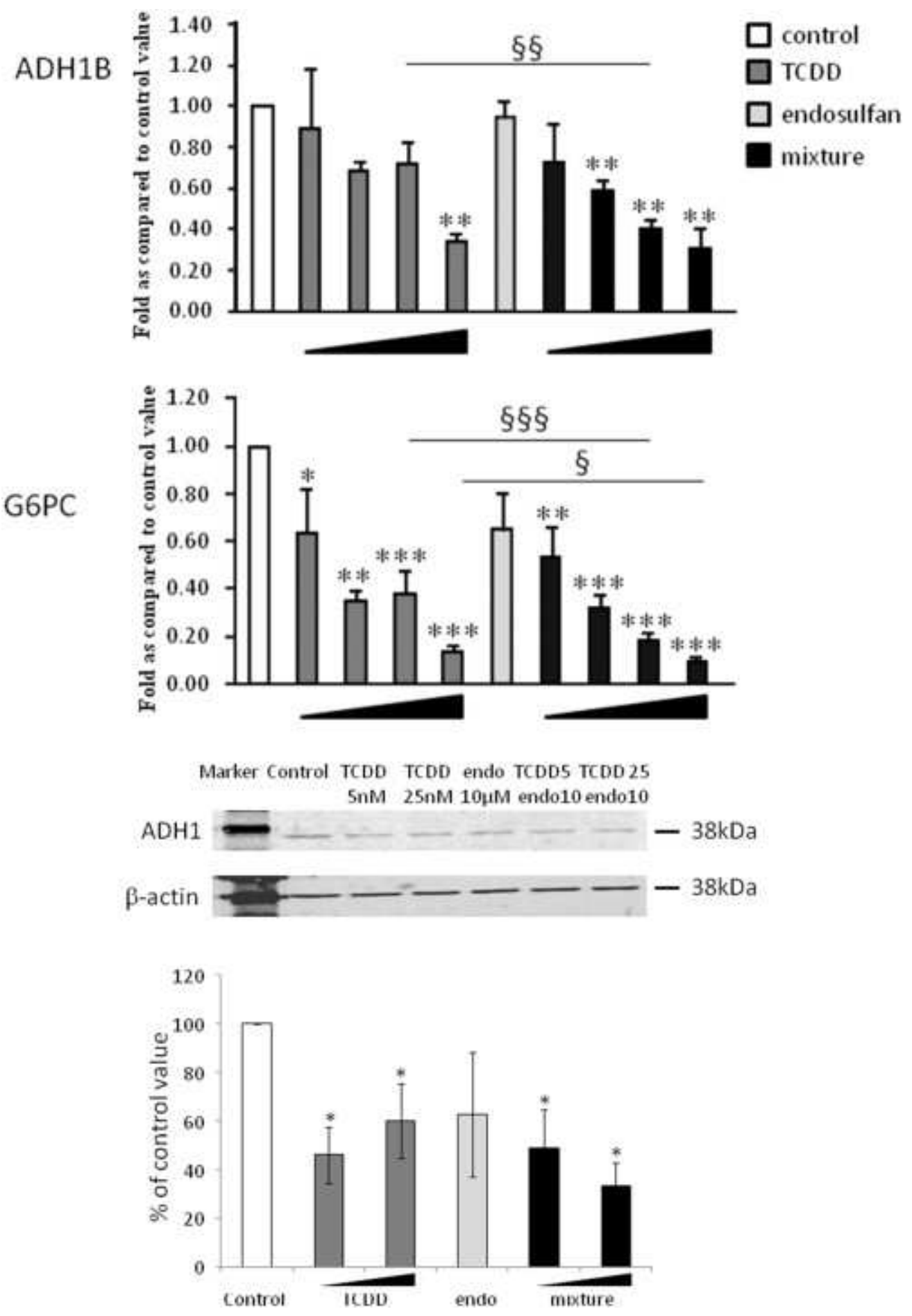

Figure 4. mRNA and protein levels of ADH1B and G6PC after pollutant exposure. A. HepaRG cells were exposed for 8 days to DMSO $(0.15 \%)$, to a range $(0.2,0.5,1$, and $5 \mathrm{nM})$ of TCDD concentrations, to $1 \mu \mathrm{M} \alpha$-endosulfan or to the combination of $1 \mu \mathrm{M} \alpha$-endosulfan with the various concentrations of TCDD. The levels of mRNA, as measured by RT-qPCR, are expressed as the fold-change as compared to the control value. * represents the level of significance of the fold-change as compared to the control $(*, \mathrm{p}<0.05, * *, \mathrm{p}<0.01, * * *, \mathrm{p}<$ $0.001)$ and $\$$ represents the the level of significance of the fold-change of the mixture as 
compared to TCDD treatment alone $(\S, \mathrm{p}<0.05, \S \S, \mathrm{p}<0.01, \S \S \S, \mathrm{p}<0.001)$. The values are the

results of 5 independent experiments performed in triplicate. B. HepaRG cells were exposed for $72 \mathrm{H}$ to DMSO $(0.15 \%)$, TCDD (5 or $25 \mathrm{nM}), \alpha$-endosulfan $(10 \mu \mathrm{M})$ or the mixtures. A typical Western blot analysis of the ADH1 protein is shown above and, below, the quantification of 3 independent experiments. ${ }^{*}, \mathrm{p}<0.05$. 


\section{Tables}

Table 1

Genes regulated in cells following exposure to either TCDD or $\alpha$-endosulfan alone and to their combination

\begin{tabular}{|c|c|c|c|}
\hline Gene symbol & Gene name & mRNA f & change by \\
\hline Genes regulat & either TCDD or the combination TCDD plus $\alpha$-endosulfan & TCDD & combination \\
\hline CYP1A2 & cytochrome P450, family 1 , subfamily A, polypeptide 2 & 51.40 & 34.27 \\
\hline CYP1A1 & cytochrome P450, family 1 , subfamily A, polypeptide 1 & 37.55 & 38.48 \\
\hline STC2 & stanniocalcin 2 & 29.30 & 43.20 \\
\hline SERPINB2 & serpin peptidase inhibitor, clade B (ovalbumin), member 2 & 26.07 & 38.3 \\
\hline TMEM156 & transmembrane protein 156 & 13.37 & 16.72 \\
\hline SLC37A2 & solute carrier family 37 (glycerol-3-phosphate transporter), member 2 & 8.70 & 16.36 \\
\hline ALDH3A1 & aldehyde dehydrogenase 3 family, memberA1 & 6.49 & 5.88 \\
\hline C3orf59 & chromosome 3 open reading frame 59 & 6.42 & 6.41 \\
\hline MBL2 & mannose-binding lectin (protein C) 2, soluble (opsonic defect) & 6.07 & 5.33 \\
\hline IGFBP1 & insulin-like growth factor binding protein 1 & 4.28 & 3.51 \\
\hline SLC7A5 & solute carrier family 7 (cationic amino acid transporter, y+ system), member 5 & 3.98 & 4.79 \\
\hline TIPARP & TCDD-inducible poly(ADP-ribose) polymerase & 3.90 & 4.19 \\
\hline CYBASC3 & cytochrome $b$, ascorbate dependent 3 & 3.89 & 4.01 \\
\hline IER $3^{a}$ & immediate early response 3 & $3.25-3.27$ & $4.08-4.12$ \\
\hline RAP1GAP & RAP1 GTPase activating protein & 2.84 & 3.26 \\
\hline GDF15 & growth differentiation factor 15 & 2.81 & 3.55 \\
\hline SYT12 & synaptotagmin XII & 2.66 & 3.26 \\
\hline HSD17B2 & hydroxysteroid (17-beta) dehydrogenase 2 & 2.63 & 2.49 \\
\hline PAPPA & pregnancy-associated plasma protein A, pappalysin 1 & 2.51 & 2.64 \\
\hline GRIA3 & glutamate receptor, ionotrophic, AMPA 3 & 2.40 & 2.56 \\
\hline SLC7A11 & solute carrier family 7, (cationic amino acid transporter, $y+$ system) member 11 & 2.38 & 3.75 \\
\hline ASAM & adipocyte-specific adhesion molecule & 2.36 & 2.67 \\
\hline VWCE & von Willebrand factor $\mathrm{C}$ and EGF domains & 2.32 & 2.39 \\
\hline
\end{tabular}




\begin{tabular}{|c|c|c|c|}
\hline BMF & Bcl2 modifying factor & 2.31 & 2.38 \\
\hline EREG & epiregulin & 2.31 & 2.40 \\
\hline RUNX2 & runt-related transcription factor 2 & 2.26 & 2.14 \\
\hline MCCC1 & methylcrotonoyl-Coenzyme A carboxylase 1 (alpha) & 2.18 & 2.14 \\
\hline AKR1B10 & aldo-keto reductase family 1 , member B 10 (aldose reductase) & 2.18 & 2.57 \\
\hline PNMA2 & paraneoplastic antigen MA2 & 2.15 & 2.45 \\
\hline STON2 & stonin 2 & 2.11 & 2.23 \\
\hline CYP19A1 & cytochrome P450, family 19, subfamily A, polypeptide 1 & 2.11 & 2.48 \\
\hline SLC6A6 & solute carrier family 6 (neurotransmitter transporter, taurine), member 6 & 2.07 & 2.46 \\
\hline TMEM138 & transmembrane protein 138 & 2.07 & 2.32 \\
\hline PLEKHF1 & pleckstrin homology domain containing, family F (with FYVE domain) member 1 & 2.05 & 2.48 \\
\hline NPTX2 & neuronal pentraxin II & 2.04 & 2.66 \\
\hline UGCG & UDP-glucose ceramide glucosyltransferase & 2.04 & 2.38 \\
\hline GPR175 & G protein-coupled receptor 175 & 2.03 & 2.21 \\
\hline SLCO2B1 & solute carrier organic anion transporter family, member $2 \mathrm{~B} 1$ & 0.50 & 0.44 \\
\hline PLGLA & plasminogen-like A & 0.49 & 0.49 \\
\hline MCTP1 & multiple $\mathrm{C} 2$ domains, transmembrane 1 & 0.49 & 0.50 \\
\hline SLC22A7 & solute carrier family 22 (organic anion transporter), member 7 & 0.48 & 0.28 \\
\hline CYP4X1 & cytochrome P450, family 4 , subfamily X, polypeptide 1 & 0.48 & 0.36 \\
\hline ABCG8 & ATP-binding cassette, sub-family G (WHITE), member 8 & 0.47 & 0.33 \\
\hline SLC38A4 & solute carrier family 38, member 4 & 0.45 & 0.26 \\
\hline ACOT12 & acyl-CoA thioesterase 12 & 0.45 & 0.43 \\
\hline ADRA1A & adrenergic, alpha-1A-, receptor & 0.44 & 0.39 \\
\hline KDR & kinase insert domain receptor (a type III receptor tyrosine kinase) & 0.44 & 0.41 \\
\hline ABCG5 & ATP-binding cassette, sub-family G (WHITE), member 5 & 0.44 & 0.30 \\
\hline FABP1 & fatty acid binding protein 1 , liver & 0.43 & 0.27 \\
\hline LEAP2 & liver expressed antimicrobial peptide 2 & 0.42 & 0.30 \\
\hline SERPINA7 & serpin peptidase inhibitor, clade A (alpha- 1 antiproteinase, antitrypsin), member 7 & 0.42 & 0.33 \\
\hline FMO5 & flavin containing monooxygenase 5 & 0.41 & 0.38 \\
\hline LOC 100129488 & hypothetical protein LOC100129488 & 0.41 & 0.27 \\
\hline GPD1 & glycerol-3-phosphate dehydrogenase 1 (soluble) & 0.39 & 0.31 \\
\hline SLC2A2 & solute carrier family 2 (facilitated glucose transporter), member 2 & 0.38 & 0.21 \\
\hline SLC10A1 & solute carrier family 10 (sodium/bile acid cotransporter family), member 1 & 0.38 & 0.47 \\
\hline
\end{tabular}




\begin{tabular}{|c|c|c|c|}
\hline THRSP & thyroid hormone responsive (SPOT14 homolog, rat) & 0.36 & 0.39 \\
\hline CXCL13 & chemokine (C-X-C motif) ligand 13 & 0.35 & 0.41 \\
\hline $\mathrm{HAO} 2$ & hydroxyacid oxidase 2 (long chain) & 0.34 & 0.17 \\
\hline CTGF & connective tissue growth factor & 0.34 & 0.37 \\
\hline DNAJC15 & DnaJ (Hsp40) homolog, subfamily C, member 15 & 0.32 & 0.41 \\
\hline RDH16 & retinol dehydrogenase 16 (all-trans) & 0.31 & 0.16 \\
\hline MFSD2 & major facilitator superfamily domain containing 2 & 0.30 & 0.25 \\
\hline CYP4B1 & cytochrome P450, family 4 , subfamily B, polypeptide 1 & 0.28 & 0.36 \\
\hline PFKFB1 & 6-phosphofructo-2-kinase/fructose-2,6-biphosphatase 1 & 0.26 & 0.31 \\
\hline DKK1 & dickkopf homolog 1 (Xenopus laevis) & 0.18 & 0.20 \\
\hline & & \multicolumn{2}{|c|}{ mRNA fold-change by } \\
\hline \multicolumn{2}{|c|}{ Genes regulated by either $\alpha$-endosulfan or the combination TCDD plus $\alpha$-endosulfan } & $\alpha$-endosulfan & combination \\
\hline GPX2 & glutathione peroxidase 2 (gastrointestinal) & 2.36 & 2.04 \\
\hline CYP2B6 & cytochrome P450, family 2 , subfamily B, polypeptide 6 & 2.14 & 2.35 \\
\hline LOC221442 & hypothetical LOC221442 & 2.08 & 2.11 \\
\hline CYP2E1 & cytochrome P450, family 2 , subfamily E, polypeptide 1 & 0.49 & 0.19 \\
\hline LOC441120 & hypothetical LOC441120 & 0.35 & 0.41 \\
\hline
\end{tabular}

The mRNA fold change for each gene corresponds to the ratio of mRNA expression for cells exposed to each treatment (25nM TCDD or $10 \mu \mathrm{M} \alpha$ endosulfan or their combination) versus that for untreated cells $(0.15 \%$ DMSO). The values (fold change $>2$ for up-regulated genes or $<0.5$ for downregulated genes) are the means of three microarray experiments. All the genes are significantly differentially expressed with $\mathrm{p}<0.05$ by Fisher t-test analysis. ${ }^{\text {a }}$ Values correspond to several probes in the microarray. 
Table 2

Genes differentially down-regulated in HepaRG cells following exposure to either 25nM

TCDD or $10 \mu \mathrm{M} \alpha$-endosulfan or their combination for 30 hours)

\begin{tabular}{llccc}
\hline Gene symbol & Gene name & \multicolumn{2}{c}{ mRNA fold change } \\
\hline & & TCDD & $\begin{array}{c}\boldsymbol{\alpha} \text { - } \\
\text { endosulfan }\end{array}$ & combination \\
\hline G6PC & glucose-6-phosphatase, catalytic subunit & 0.23 & 0.38 & 0.09 \\
ADH4 & alcohol dehydrogenase 4 (class II), pi polypeptide & 0.38 & 0.40 & 0.13 \\
HMGCS2 & 3-hydroxy-3-methylglutaryl-Coenzyme A synthase 2 & 0.50 & 0.46 & 0.19 \\
GNMT & (mitochondrial) & 0.33 & 0.43 & 0.20 \\
CPS1 & glycine N-methyltransferase & 0.35 & 0.47 & 0.22 \\
AFM & carbamoyl-phosphate synthetase 1, mitochondrial & 0.50 & 0.48 & 0.27 \\
\hline
\end{tabular}

All these genes exhibit at least a 2-fold change in expression for cells exposed to all 3

treatments as compared to the control condition. The values are the means of three microarray experiments $(\mathrm{p} \leq 0.05)$. Down-regulated genes show a fold change $<1$ as compared to the control condition. 
Table 3

Focus analysis top regulated genes differentially expressed following exposure of cells to the combination of TCDD $+\alpha$-endosulfan as compared to all other treatments

\begin{tabular}{|c|c|c|}
\hline Gene symbol & Gene name / function & $\begin{array}{l}\text { mRNA fold change by } \\
\text { TCDD }+\alpha \text {-endosulfan }\end{array}$ \\
\hline \multicolumn{3}{|c|}{ Up-regulated genes } \\
\hline STC2* & stanniocalcin 2 / oxidative stress & 43.20 \\
\hline SERPINB2* & serpine peptidase inhibitor, member 2 / cell migration & 38.30 \\
\hline SLC37A2* & solute carrier family 37 , member 2 / stress response & 16.36 \\
\hline SLC7A11* & $\begin{array}{l}\text { solute carrier family } 7 \text {, (cationic amino acid transporter, y+ system) member } \\
11 / \text { oxidative stress }\end{array}$ & 3.75 \\
\hline GDF15* & growth differentiation factor 15 / stress response & 3.55 \\
\hline AKR1B10* & aldo-keto reductase family 1 , member B10/ fatty acid biosynthesis & 2.57 \\
\hline CA12 & carbonic anhydrase XII / hypoxic stress & 2.45 \\
\hline serpine 1 & serpine peptidase inhibitor / cell migration & 1.89 \\
\hline MT1A & metallothionein $1 \mathrm{~A} /$ oxidative stress & 1.83 \\
\hline ST3GAL5 & $\begin{array}{l}\text { ST3 beta-galactoside alpha-2,3-sialyltransferase } 5 \text { / cell differenciation \& } \\
\text { proliferation }\end{array}$ & 1.78 \\
\hline \multicolumn{3}{|c|}{ Down-regulated genes } \\
\hline $\mathrm{G} 6 \mathrm{PC}^{\$}$ & glucose 6 phosphatase, catalytic chain / glucose metabolism & 0.09 \\
\hline $\mathrm{ADH} 4{ }^{\$}$ & alcohol dehydrogenase $4 /$ retinoid and alcohol metabolism & 0.13 \\
\hline $\mathrm{HAO} 2 *$ & hydroxyacid oxidase 2 / fatty acid oxidation & 0.17 \\
\hline HMGCS $2 \$$ & 3-hydroxy-3-methylglutaryl-CoA synthase 2 /ketone bodies synthesis & 0.19 \\
\hline CYP2E1 & cytochrome P450 2E1/ alcohol metabolism & 0.19 \\
\hline SLC2A2* & solute carrier family 7 , (facilitated glucose transporter) member 2 & 0.21 \\
\hline ADH1A & alcohol dehydrogenase $1 \mathrm{~A} /$ retinoid and alcohol metabolism & 0.28 \\
\hline ADH1B & alcohol dehydrogenase 1B / retinoid and alcohol metabolism & 0.33 \\
\hline ADH1C & alcohol dehydrogenase $1 \mathrm{C} /$ retinoid and alcohol metabolism & 0.38 \\
\hline HSD17B6 & hydroxysteroid (17-beta) dehydrogenase 6 homolog / retinoid metabolism & 0.41 \\
\hline
\end{tabular}

Genes in bold, *, and $\$$, were found to be differentially expressed in cells exposed to the mixture, to TCDD alone or the mixture or to all 3 treatments, respectively by t-test analysis.

CYP2E1 was found to be altered following treatment with $\alpha$-endosulfan alone and the mixture by t-test analysis. The values are the fold change by the combination compared to the control condition. Up-regulated and down-regulated genes show fold changes $>1$ and $<1$, respectively, as compared to the control condition. 


\section{Table 4}

Top canonical pathways regulated in cells exposed to the combination of TCDD and $\alpha$ endosulfan

\begin{tabular}{lcc}
\hline Name of pathway & p-value & ratio $^{\mathbf{a}}$ \\
\hline by Up-regulated genes & & \\
\hline Pyrimidine metabolism & $2.05 \mathrm{E}-07$ & $18 / 231$ \\
Role of CHK proteins in cell cycle checkpoint control & $2.05 \mathrm{E}-06$ & $8 / 35$ \\
RAN signaling & $4.82 \mathrm{E}-05$ & $5 / 23$ \\
AhR signaling & $6.96 \mathrm{E}-05$ & $13 / 154$ \\
Molecular mechanisms of cancer & $1.10 \mathrm{E}-04$ & $22 / 372$ \\
\hline by Down-regulated genes & & \\
\hline FXR/RXR activation & $3.31 \mathrm{E}-14$ & $12 / 103$ \\
Bile acid biosynthesis & $4.99 \mathrm{E}-09$ & $7 / 100$ \\
Metabolism of xenobiotics by CYPs & $2.52 \mathrm{E}-08$ & $9 / 209$ \\
Glycolysis/Gluconeogenesis & $4.90 \mathrm{E}-08$ & $8 / 142$ \\
Glycerolipid metabolism & $8.42 \mathrm{E}-08$ & $8 / 156$ \\
\hline
\end{tabular}

${ }^{a}$ The ratio corresponds to the number of genes regulated by the combination of TCDD plus $\alpha$ endosulfan as compared to the total number of genes in the specific pathway, found by the Ingenuity Pathway Analysis. 


\section{Supplementary Tables}

Table S1

Primer sequences for RT-qPCR assays

\begin{tabular}{|c|c|c|}
\hline Gene & Forward Primer (5'-3') & Reverse Primer (5'-3') \\
\hline ADH1A & GGCATCAGCACCTTCTCAC & GACCTTGGCAACATTGACTG \\
\hline ADH1B & GGCAGAGAAGACAGAAACGAC & CAАССТССАСАТССТСАATG \\
\hline ADH1C & CTGCTTCGCTCTGGAAAG & GAGGAGGCTGAAAACTGC \\
\hline ADH4 & GCATTGAAGAGGTTGAAGTAGC & GATAACAGTGGCATCAGTATGG \\
\hline ADH6 & GGAAGTTCGCATAAAGGTTG & CAAGATGGTGGGATACAAGAG \\
\hline CYP2E1 & ACTATGGGATGGGGAAACAG & GAGGATGTCGGCTATGACG \\
\hline SERPINB2 & GCTGTTTGGTGAGAAGTCTG & GCCTTTGGTTTGAGTCTTG \\
\hline STC2 & GGAAGAGGGGAGCACAAAG & CAGCGTTGACCAAACAGTG \\
\hline SLC7A11 & TGGCAGTGACCTTTTCTGAG & CCTGGAGACAGCAAACACAC \\
\hline DTL & GTCCCAGTTCCTCCTTTTG & CCAGTGAGCCATCCATTC \\
\hline SLC9A9 & GCTGCTCCTCGTGTTCTTC & TGCTTCCTGGTGTTGTGAG \\
\hline ABCG8 & GCCTCCTTCTTCAGCAATG & TCAGCCCTTCAAAACACC \\
\hline ALDH3A1 & CAGAAGGTGGCTTATGGG & ACGCTGGTTGATGAACTG \\
\hline AFM & ATGAAGTTGCCAGAAGGAAC & ATTGTGTGACAGGTATTGCC \\
\hline AQP9 & GCAGCTTAGCGAAAGAAACC & TGCAACTGCCATTGAAAATC \\
\hline GPX2 & TTTGGACATCAGGAGAACTG & TTCAGGTAGGCGAAGACAG \\
\hline MBL2 & ATGGTGGCAGCGTCTTAC & CCTGGTTCCCCCTTTTC \\
\hline $\operatorname{SLC22A7}$ & CGTTGGGGGAAGAAAGG & CGGCGAAGAAGAAAGTGG \\
\hline SLC38A4 & GCAGTCCTTGTGGCAGTAAC & CCCCTATGAATCCGAAGATG \\
\hline G6PC & TTGTGGTTGGGATTCTGG & CTGTGGATGTGGCTGAAAG \\
\hline SDS & ATGAAGGTGCCACAGTCAAG & TCAAAGGGGGGAATGTAGAC \\
\hline HMGCS2 & CCCGTCTAAAGGTGTTCTG & AGCCCAGGACAGTGATTG \\
\hline CYP1A1 & GGTCAAGGAGCACTACAAAACC & TGGACATTGGCGTTCTCAT \\
\hline CYP1A2 & ACAGCACAACAAGGGACACA & TGCCAAACAGCATCATCTTC \\
\hline CYP3A4 & GATGGCTCTCATCCCAGACTT & AGTCCATGTGAATGGGTTCC \\
\hline CYP2B6 & TTCAGGAGGAGGCTCAGTGT & GGCCGAATACAGAGCTGATG \\
\hline RPL13A & AAGGTCGTGCGTCTGAAG & GAGTCCGTGGGTCTTGAG \\
\hline GDF15 & GCTACGAGGACCTGCTAAC & ACTTCTGGCGTGAGTATCC \\
\hline NEIL3 & TTCCAGCCAGAATGTCTTGAG & CCGAAATGAATCCGTAAAGC \\
\hline HAO2 & CCTGAACTGTGGGTAGTGATG & GCCTGAAAGTCTGTCAAACAC \\
\hline SLC2A2 & CACTTGGCACTTTTCATCAG & AGGTATCTGGGGCTTTCTG \\
\hline CA12 & TCTTGGCATCTGTATTGTGG & GGCTGGCTTGTAAATGACTC \\
\hline CYP7A1 & CCATTCCAGCGACTTTCTG & AGCCTCAGCGATTCCTTG \\
\hline PON1 & CATAAAAGTGCTCAGGTCCCACAG & TGGAATTGGGGATCACTGGAAG \\
\hline SULT2A1 & CCTGAACTGTGGGTAGTGATG & GCCTGAAAGTCTGTCAAACAC \\
\hline
\end{tabular}




\section{Table S2}

Genes exhibiting at least a 2-fold change in expression in HepaRG cells exposed for 30 hours to either 25nM TCDD only or $10 \mu \mathrm{M} \alpha$-endosulfan only or the combination of TCDD plus $\alpha$-endosulfan only

\begin{tabular}{|c|c|c|c|c|}
\hline \multirow[t]{2}{*}{ Gene symbol } & \multirow[t]{2}{*}{ Gene name } & \multicolumn{3}{|c|}{ mRNA fold change by } \\
\hline & & TCDD & $\alpha$-endosulfan & combination \\
\hline \multicolumn{5}{|c|}{ Genes regulated by TCDD only } \\
\hline KRTAP21-1 & keratin associated protein $21-1$ & 3.65 & $3.97 *$ & $3.51 *$ \\
\hline TRPV6 & transient receptor potential cation channel, subfamily $\mathrm{V}$, member 6 & 2.40 & 0.92 & 1.15 \\
\hline$\underline{\mathrm{S} 100 \mathrm{~A} 8}$ & S100 calcium binding protein $\mathrm{A} 8$ & 2.26 & 0.83 & 1.84 \\
\hline$\underline{\mathrm{HK} 2}$ & hexokinase 2 & 2.24 & 0.92 & $2.23 *$ \\
\hline$\underline{\mathrm{UBE} 2 \mathrm{U}}$ & ubiquitin-conjugating enzyme E2U (putative) & 2.23 & 1.16 & 1.43 \\
\hline SCN1A & sodium channel, voltage-gated, type I, alpha subunit & 2.11 & 1.17 & 1.62 \\
\hline SLC22A3 & solute carrier family 22 (extraneuronal monoamine transporter), member 3 & 0.50 & 0.99 & 0.55 \\
\hline RASGEF1B & RasGEF domain family, member 1B & 0.50 & 1.00 & 0.59 \\
\hline CLEC4E & C-type lectin domain family 4 , member $\mathrm{E}$ & 0.50 & $0.50 *$ & $0.37 *$ \\
\hline ABI3BP & ABI family, member $3(\mathrm{NESH})$ binding protein & 0.50 & 1.00 & 0.59 \\
\hline SLC16A12 & solute carrier family 16, member 12 (monocarboxylic acid transporter 12 ) & 0.49 & 1.44 & 0.65 \\
\hline MRC1 & mannose receptor, $\mathrm{C}$ type 1 & 0.49 & 0.73 & $0.42 *$ \\
\hline $\mathrm{ABCD} 2$ & ATP-binding cassette, sub-family D (ALD), member 2 & 0.49 & 0.98 & 0.54 \\
\hline MCF2 & MCF. 2 cell line derived transforming sequence & 0.49 & 0.94 & 0.54 \\
\hline CIDEC & cell death-inducing DFFA-like effector c & 0.48 & 1.10 & 0.63 \\
\hline OR10R2 & olfactory receptor, family 10 , subfamily $\mathrm{R}$, member 2 & 0.48 & 0.83 & $0.39 *$ \\
\hline KCNB1 & potassium voltage-gated channel, Shab-related subfamily, member 1 & 0.48 & 1.41 & 0.82 \\
\hline GHR & growth hormone receptor & 0.48 & 1.03 & 0.56 \\
\hline OR7E18P & olfactory receptor, family 7 , subfamily E, member 18 pseudogene & 0.48 & 1.00 & 0.90 \\
\hline GYS2 & glycogen synthase 2 (liver) & 0.46 & 1.34 & 0.56 \\
\hline
\end{tabular}




\begin{tabular}{|c|c|c|c|c|}
\hline$\underline{\text { GZMK }}$ & granzyme K (granzyme 3; tryptase II) & 0.43 & 0.63 & 0.81 \\
\hline \multicolumn{5}{|c|}{ Genes regulated by $\alpha$-endosulfan only } \\
\hline OR2T4 & olfactory receptor, family 2 , subfamily $\mathrm{T}$, member 4 & 1.59 & 2.44 & $2.03 *$ \\
\hline$\underline{\text { SFRP4 }}$ & secreted frizzled-related protein 4 & 0.79 & 2.19 & 1.65 \\
\hline NCRNA00052 & non-protein coding RNA 52 & 0.63 & 0.50 & 0.68 \\
\hline CPA3 & carboxypeptidase A3 (mast cell) & 1.04 & 0.50 & 0.90 \\
\hline LIPI & lipase, member I & 1.22 & 0.49 & 0.85 \\
\hline FAM99A & family with sequence similarity 99 , member A & $3.01 *$ & 0.27 & 0.62 \\
\hline CNGA1 & cyclic nucleotide gated channel alpha 1 & 0.57 & 0.47 & $0.50 *$ \\
\hline$\underline{\text { FAM71D }}$ & family with sequence similarity 71 , member $D$ & 1.08 & 0.44 & 0.69 \\
\hline$\underline{\mathrm{LOC} 651503}$ & seven transmembrane helix receptor & 1.42 & 0.34 & 0.94 \\
\hline$\underline{\mathrm{LOC} 441233}$ & hypothetical gene supported by AK128010 & 0.76 & 0.25 & $0.43 *$ \\
\hline \multicolumn{5}{|c|}{ Genes regulated by the combination TCDD plus $\alpha$-endosulfan only } \\
\hline LOC100130904 & similar to CD177 molecule & $2.64 *$ & $2.39^{*}$ & 3.64 \\
\hline VDR & vitamin D (1,25- dihydroxyvitamin D3) receptor & $2.58 *$ & 1.26 & 3.38 \\
\hline LOC732275 & similar to hCG1645603 & 0.98 & 1.31 & 3.04 \\
\hline DTL & denticleless homolog (Drosophila) & 1.42 & 1.76 & 2.99 \\
\hline FAM111B & family with sequence similarity 111 , member B & 1.58 & 1.87 & 2.83 \\
\hline SLC9A9 & solute carrier family 9 (sodium/hydrogen exchanger), member 9 & $2.11 *$ & 1.29 & 2.75 \\
\hline GPRC5B & G protein-coupled receptor, family $\mathrm{C}$, group 5 , member $\mathrm{B}$ & 1.42 & $2.18^{*}$ & 2.72 \\
\hline E2F7 & E2F transcription factor 7 & 1.65 & 1.61 & 2.71 \\
\hline EXO1 & exonuclease 1 & 1.56 & $2.06^{*}$ & 2.68 \\
\hline DCLK1 & doublecortin-like kinase 1 & 1.61 & 1.87 & 2.62 \\
\hline NEIL3 & nei endonuclease VIII-like 3 (E. coli) & 1.69 & 1.92 & 2.62 \\
\hline $\mathrm{XRCC} 2$ & $\mathrm{X}$-ray repair complementing defective repair in Chinese hamster cells 2 & 1.51 & 1.66 & 2.57 \\
\hline RIBC2 & RIB43A domain with coiled-coils 2 & 1.62 & 1.84 & 2.55 \\
\hline
\end{tabular}




\begin{tabular}{|c|c|c|c|c|}
\hline PTPRE & protein tyrosine phosphatase, receptor type, E & $2.02 *$ & 1.35 & 2.47 \\
\hline SEC14L4 & SEC14-like 4 (S. cerevisiae) & $2.18^{*}$ & 1.41 & 2.46 \\
\hline RAD51 & RAD51 homolog (RecA homolog, E. coli) (S. cerevisiae) & 1.41 & 1.86 & 2.45 \\
\hline CA12 & carbonic anhydrase XII & 1.73 & 1.61 & 2.45 \\
\hline PFKP & phosphofructokinase, platelet & 1.87 & 1.30 & 2.35 \\
\hline FBXW10 & F-box and WD repeat domain containing 10 & 1.51 & 1.59 & 2.31 \\
\hline C22orf9 & chromosome 22 open reading frame 9 & 1.93 & 1.18 & 2.29 \\
\hline ORC1L & origin recognition complex, subunit 1-like (yeast) & 1.42 & 1.49 & 2.27 \\
\hline HIST1H3A & histone cluster $1, \mathrm{H} 3 \mathrm{a}$ & 1.28 & 1.64 & 2.26 \\
\hline G6PC2 & glucose-6-phosphatase, catalytic, 2 & $2.13 *$ & $2.06 *$ & 2.22 \\
\hline HIST1H3B & histone cluster $1, \mathrm{H} 3 \mathrm{~b}$ & 1.31 & 1.64 & 2.21 \\
\hline CDRT1 & CMT1A duplicated region transcript 1 & 1.46 & 1.68 & 2.19 \\
\hline CCL20 & chemokine (C-C motif) ligand 20 & 1.57 & 1.35 & 2.14 \\
\hline SSH1 & slingshot homolog 1 (Drosophila) & 1.55 & 1.22 & 2.13 \\
\hline ARMC9 & armadillo repeat containing 9 & 1.81 & 1.05 & 2.12 \\
\hline ALPP & alkaline phosphatase, placental (Regan isozyme) & 1.44 & 1.40 & 2.12 \\
\hline ARSI & arylsulfatase family, member I & $2.42 *$ & 0.92 & 2.12 \\
\hline MCM5 & minichromosome maintenance complex component 5 & 1.39 & 1.56 & 2.11 \\
\hline FAM46C & family with sequence similarity 46 , member $\mathrm{C}$ & 1.86 & 1.21 & 2.11 \\
\hline ADAM12 & ADAM metallopeptidase domain 12 & 1.72 & 1.54 & 2.08 \\
\hline CDC6 & cell division cycle 6 homolog (S. cerevisiae) & 1.27 & 1.50 & 2.07 \\
\hline MLLT1 & $\begin{array}{l}\text { myeloid/lymphoid or mixed-lineage leukemia (trithorax homolog, Drosophila); } \\
\text { translocated to, } 1\end{array}$ & 1.87 & 1.20 & 2.06 \\
\hline MYC & v-myc myelocytomatosis viral oncogene homolog (avian) & 1.74 & 1.40 & 2.06 \\
\hline $\mathrm{NCF} 2$ & neutrophil cytosolic factor 2 & 1.32 & 1.41 & 2.06 \\
\hline CDCA7 & cell division cycle associated 7 & 1.55 & 1.57 & 2.05 \\
\hline WDR76 & WD repeat domain 76 & 1.22 & 1.54 & 2.05 \\
\hline MCM2 & minichromosome maintenance complex component 2 & 1.45 & 1.35 & 2.05 \\
\hline
\end{tabular}




\begin{tabular}{|c|c|c|c|c|}
\hline SRXN1 & sulfiredoxin 1 homolog (S. cerevisiae) & 1.55 & 1.48 & 2.03 \\
\hline CCNE2 & cyclin E2 & 1.20 & 1.36 & 2.03 \\
\hline CFHR3 & complement factor H-related 3 & 0.64 & 0.74 & 0.50 \\
\hline CYP2A6 & cytochrome P450, family 2, subfamily A, polypeptide 6 & 0.54 & 0.92 & 0.50 \\
\hline AHSG & alpha-2-HS-glycoprotein & 0.62 & 0.66 & 0.50 \\
\hline CYP2A13 & cytochrome P450, family 2, subfamily A, polypeptide 13 & 0.55 & 0.91 & 0.50 \\
\hline DGAT2 & diacylglycerol O-acyltransferase homolog 2 (mouse) & 0.57 & 0.80 & 0.50 \\
\hline PDE8B & phosphodiesterase 8B & 0.51 & 1.00 & 0.50 \\
\hline ABCC9 & ATP-binding cassette, sub-family C (CFTR/MRP), member 9 & 0.55 & 0.92 & 0.49 \\
\hline C12orf27 & chromosome 12 open reading frame 27 & 0.61 & 0.88 & 0.49 \\
\hline HFE2 & hemochromatosis type 2 (juvenile) & 0.56 & 0.65 & 0.49 \\
\hline CIDEB & cell death-inducing DFFA-like effector b & 0.61 & 0.82 & 0.49 \\
\hline SLCO1B1 & solute carrier organic anion transporter family, member 1B1 & 0.62 & 0.81 & 0.49 \\
\hline AQP9 & aquaporin 9 & 0.53 & 0.97 & 0.49 \\
\hline C7orf45 & chromosome 7 open reading frame 45 & 0.78 & 0.74 & 0.49 \\
\hline RORC & RAR-related orphan receptor C & 0.61 & 0.72 & 0.48 \\
\hline SLC38A3 & solute carrier family 38, member 3 & 0.64 & 0.77 & 0.48 \\
\hline ALDOB & aldolase $\mathrm{B}$, fructose-bisphosphate & 0.59 & 0.80 & 0.48 \\
\hline CCIN & calicin & 0.87 & 0.68 & 0.48 \\
\hline LST-3TM12 & organic anion transporter LST-3b & 0.64 & 0.80 & 0.48 \\
\hline CYP2A7 & cytochrome P450, family 2, subfamily A, polypeptide 7 & 0.51 & 0.91 & 0.48 \\
\hline SELENBP1 & selenium binding protein 1 & 0.53 & 0.91 & 0.48 \\
\hline CALML4 & calmodulin-like 4 & 0.56 & 0.82 & 0.47 \\
\hline ANG & angiogenin, ribonuclease, RNase A family, 5 & 0.60 & 0.74 & 0.47 \\
\hline CDC20B & cell division cycle 20 homolog B (S. cerevisiae) & 0.67 & 0.64 & 0.47 \\
\hline PLA2G12B & phospholipase A2, group XIIB & 0.60 & 0.75 & 0.46 \\
\hline DAB 1 & disabled homolog 1 (Drosophila) & 0.52 & 090 & 0.46 \\
\hline CFHR2 & complement factor H-related 2 & 0.57 & 0.90 & 0.46 \\
\hline SCGN & secretagogin, EF-hand calcium binding protein & 0.51 & 0.92 & 0.46 \\
\hline
\end{tabular}




\begin{tabular}{|c|c|c|c|c|}
\hline GLYAT & glycine-N-acyltransferase & 0.52 & 0.94 & 0.46 \\
\hline LOC441178 & hypothetical LOC441178 & 0.67 & 0.52 & 0.46 \\
\hline OTC & ornithine carbamoyltransferase & 0.57 & 0.70 & 0.45 \\
\hline PKLR & pyruvate kinase, liver and RBC & 0.74 & 0.71 & 0.45 \\
\hline PON1 & paraoxonase 1 & 0.6 & 0.75 & 0.45 \\
\hline GLYATL1 & glycine- $\mathrm{N}$-acyltransferase-like 1 & 0.51 & 0.75 & 0.45 \\
\hline SLC10A5 & solute carrier family 10 (sodium/bile acid cotransporter family), member 5 & 0.59 & 0.75 & 0.44 \\
\hline SLC22A10 & solute carrier family 22, member 10 & 0.66 & 0.53 & 0.44 \\
\hline AGXT2 & alanine-glyoxylate aminotransferase 2 & 0.55 & 0.84 & 0.43 \\
\hline HRG & histidine-rich glycoprotein & 0.64 & 0.61 & 0.43 \\
\hline ANGPTL5 & angiopoietin-like 5 & 0.96 & 1.11 & 0.41 \\
\hline ARG1 & arginase, liver & 0.56 & 0.72 & 0.41 \\
\hline HSD17B6 & hydroxysteroid (17-beta) dehydrogenase 6 homolog (mouse) & 0.57 & 0.74 & 0.41 \\
\hline PCK2 & phosphoenolpyruvate carboxykinase 2 (mitochondrial) & 0.51 & 0.73 & 0.41 \\
\hline SULT1E1 & sulfotransferase family $1 \mathrm{E}$, estrogen-preferring, member 1 & $0.48^{*}$ & 0.72 & 0.41 \\
\hline SLC17A4 & solute carrier family 17 (sodium phosphate), member 4 & 0.53 & 0.83 & 0.40 \\
\hline SLC5A9 & solute carrier family 5 (sodium/glucose cotransporter), member 9 & 0.53 & 0.83 & 0.40 \\
\hline LRRC31 & leucine rich repeat containing 31 & 0.54 & 0.68 & 0.40 \\
\hline BDH1 & 3-hydroxybutyrate dehydrogenase, type 1 & 0.59 & 0.69 & 0.39 \\
\hline HSD3B1 & hydroxy-delta-5-steroid dehydrogenase, 3 beta- and steroid delta-isomerase 1 & 0.62 & 0.71 & 0.39 \\
\hline $\mathrm{ADH} 1 \mathrm{C}$ & alcohol dehydrogenase 1C (class I), gamma polypeptide & 0.57 & 0.71 & 0.38 \\
\hline RANBP3L & RAN binding protein 3-like & 0.51 & 0.79 & 0.38 \\
\hline PGLYRP2 & peptidoglycan recognition protein 2 & 0.62 & 0.60 & 0.37 \\
\hline BBOX1 & $\begin{array}{l}\text { butyrobetaine (gamma), 2-oxoglutarate dioxygenase (gamma-butyrobetaine } \\
\text { hydroxylase) } 1\end{array}$ & $0.40^{*}$ & 0.81 & 0.36 \\
\hline ANXA13 & annexin A13 & $0.50 *$ & 0.72 & 0.35 \\
\hline ADH6 & alcohol dehydrogenase 6 (class V) & 0.56 & 0.65 & 0.35 \\
\hline ADH1B & alcohol dehydrogenase 1B (class I), beta polypeptide & 0.65 & 0.67 & 0.33 \\
\hline PSMAL & growth-inhibiting protein 26 & 0.54 & 0.58 & 0.33 \\
\hline
\end{tabular}




\begin{tabular}{llrrr}
\hline FOLH1 & folate hydrolase (prostate-specific membrane antigen) 1 & 0.55 & 0.58 & 0.32 \\
UGT2B17 & UDP glucuronosyltransferase 2 family, polypeptide B17 & 0.69 & 0.57 \\
ADH1A & alcohol dehydrogenase 1A (class I), alpha polypeptide & 0.61 & 0.31 \\
\hline
\end{tabular}

The mRNA fold change for each gene corresponds to the ratio of mRNA expression for cells exposed to each treatment (25nM TCDD or 10 $\mu \mathrm{M}$ $\alpha$-endosulfan or the combination) versus that for untreated cells $(0.15 \%$ DMSO). The values (fold change $>2$ for up-regulated genes or $<0.5$ for down-regulated genes) are the means of three microarray experiments. All the genes are significantly differentially expressed with $\mathrm{p}<0.05$ by

Fisher t-test analysis for the treatment designated for each sub-group. For the other treatments, the fold change was either below two-fold change or not statistically significative (labeleld with an asterisk *, if p-value >0.05). The genes underlined in the first two sections of the table are those retained after filtering with increased stringency (fold change $>2.2$ or $<0.46$, p-value $<0.05$ ), see text for discussion. 
Table S3

Comparison of the changes in the expression of selected target genes by microarray and RT-qPCR analysis

\begin{tabular}{|c|c|c|c|c|c|c|c|}
\hline \multirow[b]{3}{*}{ Gene symbol } & \multirow[b]{3}{*}{ Gene name } & \multicolumn{6}{|c|}{ mRNA fold change } \\
\hline & & \multicolumn{2}{|c|}{ TCDD } & \multicolumn{2}{|c|}{$\alpha$-endosulfan } & \multicolumn{2}{|c|}{ combination } \\
\hline & & $\mu$ array & RT-qPCR & $\mu$ array & RT-qPCR & $\mu$ array & RT-qPCR \\
\hline ADH1A & alcohol dehydrogenase 1A (class I), alpha polypeptide & 0.6 & 0.40 & 0.55 & 0.18 & 0.28 & 0.09 \\
\hline ADH1B & alcohol dehydrogenase 1B (class I), beta polypeptide & 0.65 & 0.32 & 0.67 & 0.44 & 0.33 & 0.13 \\
\hline ADH1C & alcohol dehydrogenase 1C (class I), gamma polypeptide & 0.55 & 0.41 & 0.68 & 1.48 & 0.37 & 0.57 \\
\hline $\mathrm{ADH} 4$ & alcohol dehydrogenase 4 (class II), pi polypeptide & 0.38 & 0.29 & 0.40 & 0.28 & 0.13 & 0.08 \\
\hline ADH6 & alcohol dehydrogenase 6 (class V) & 0.56 & 0.49 & 0.65 & 0.62 & 0.35 & 0.29 \\
\hline CYP2E1 & cytochrome P450, family 2, subfamily E, polypeptide 1 & 0.51 & 0.41 & 0.49 & 0.34 & 0.20 & 0.10 \\
\hline CYP1A1 & cytochrome $\mathrm{P} 450$, family 1 , subfamily A, polypeptide 1 & 37.55 & 69.13 & 1.30 & 0.86 & 38.48 & 54.10 \\
\hline SERPINB2 & serpin peptidase inhibitor, clade B (ovalbumin), member 2 & 26.31 & 55.03 & 1.48 & 1.26 & 39.25 & 56.18 \\
\hline STC2 & stanniocalcin 2 & 29.56 & 47.08 & 0.63 & 1.09 & 43.20 & 80.76 \\
\hline SLC7A11 & $\begin{array}{l}\text { solute carrier family } 7 \text {, (cationic amino acid transporter, } y+\text { system) } \\
\text { member } 11\end{array}$ & 2.36 & 2.54 & 1.91 & 1.28 & 3.73 & 3.25 \\
\hline DTL & denticleless homolog (Drosophila) & 1.39 & 1.82 & 1.73 & 1.69 & 2.97 & 2.87 \\
\hline SLC9A9 & solute carrier family 9 (sodium/hydrogen exchanger), member 9 & 2.1 & 2.24 & 1.28 & 0.96 & 2.73 & 2.52 \\
\hline ABCG8 & ATP-binding cassette, sub-family G (WHITE), member 8 & 0.47 & 0.53 & 0.78 & 0.88 & 0.33 & 0.36 \\
\hline ALDH3A1 & aldehyde dehydrogenase 3 family, member A1 & 6.47 & 22.58 & 0.92 & 1.12 & 5.88 & 17.9 \\
\hline AFM & afamin & 0.5 & 0.45 & 0.48 & 0.35 & 0.27 & 0.21 \\
\hline AQP9 & aquaporin 9 & 0.53 & 0.44 & 0.97 & 0.87 & 0.48 & 0.4 \\
\hline GPX2 & glutathione peroxidase 2 (gastrointestinal) & 1.34 & 1.55 & 2.35 & 3.16 & 2.05 & 2.76 \\
\hline MBL2 & mannose-binding lectin (protein C) 2, soluble (opsonic defect) & 5.89 & 11.45 & 0.67 & 0.93 & 5.14 & 9.27 \\
\hline SLC22A7 & solute carrier family 22 (organic anion transporter), member 7 & 0.48 & 0.41 & 0.61 & 0.49 & 0.28 & 0.20 \\
\hline SLC38A4 & solute carrier family 38, member 4 & 0.44 & 0.44 & 0.59 & 0.46 & 0.26 & 0.20 \\
\hline G6PC & glucose-6-phosphatase, catalytic subunit & 0.23 & 0.18 & 0.38 & 0.23 & 0.09 & 0.04 \\
\hline SDS & serine dehydratase & 0.39 & 0.23 & 6.37 & 5.76 & 1.66 & 1.37 \\
\hline HMGCS2 & 3-hydroxy-3-methylglutaryl-Coenzyme A synthase 2 (mitochondrial) & 0.50 & 0.40 & 0.46 & 0.28 & 0.19 & 0.08 \\
\hline
\end{tabular}




\begin{tabular}{|c|c|c|c|c|c|c|c|}
\hline GDF15 & growth differentiation factor 15 & 2.81 & 3.43 & 1.38 & 0.94 & 3.55 & 5.01 \\
\hline NEIL3 & nei endonuclease VIII-like 3 (E. coli) & 1.69 & 1.56 & 1.92 & 1.34 & 2.62 & 2.25 \\
\hline $\mathrm{HAO} 2$ & hydroxyacid oxidase 2 (long chain) & 0.34 & 0.12 & 0.64 & 0.28 & 0.17 & 0.04 \\
\hline SLC2A2 & solute carrier family 2 (facilitated glucose transporter), member 2 & 0.38 & 0.26 & 0.69 & 0.45 & 0.21 & 0.12 \\
\hline CA12 & carbonic anhydrase XII & 1.73 & 1.57 & 1.61 & 1.01 & 2.45 & 2.09 \\
\hline CYP7A1 & cytochrome P450, family 7, subfamily A, polypeptide 1 & 0.66 & 0.56 & 0.28 & 0.27 & 0.21 & 0.27 \\
\hline PON1 & paraoxonase 1 & 0.64 & 0.53 & 0.75 & 0.54 & 0.45 & 0.33 \\
\hline SULT2A1 & $\begin{array}{l}\text { sulfotransferase family, cytosolic, } 2 \mathrm{~A} \text {, dehydroepiandrosterone } \\
\text { (DHEA)- preferring, member } 1\end{array}$ & 0.63 & 0.49 & 0.93 & 0.7 & 0.52 & 0.34 \\
\hline
\end{tabular}

The mRNA fold change for each gene corresponds to the ratio of mRNA expression for cells exposed to each treatment (25nM TCDD or $10 \mu \mathrm{M}$ $\alpha$-endosulfan or their combination) versus that for untreated cells $(0.15 \%$ DMSO). The values (fold change $>1$ for up-regulated genes or $<1$ for down-regulated genes) are the means of three microarray or three or more independent RT-qPCR experiments. 


\section{Table S4}

\section{Genes belonging to the top down-regulated network in cells exposed to the combination of TCDD and $\alpha$-endosulfan treatment}

\begin{tabular}{|c|c|c|c|c|}
\hline \multirow[t]{2}{*}{ Gene symbol } & \multirow[t]{2}{*}{ Gene name } & \multicolumn{3}{|c|}{ mRNA fold-change } \\
\hline & & TCDD & $\alpha$-endosulfan & combination \\
\hline G6PC & glucose-6-phosphatase, catalytic subunit & 0.23 & 0.38 & 0.009 \\
\hline $\mathrm{ADH} 4$ & alcohol dehydrogenase 4 (class II), pi polypeptide & 0.38 & 0.40 & 0.13 \\
\hline RDH16 & retinol dehydrogenase 16 (all-trans) & 0.31 & 0.55 & 0.16 \\
\hline $\mathrm{HAO} 2$ & hydroxyacid oxidase 2 (long chain) & 0.34 & 0.64 & 0.17 \\
\hline CYP7A1 & cytochrome P450, family 7 , subfamily A, polypeptide 1 & 0.65 & 0.28 & 0.21 \\
\hline CPS1 & carbamoyl-phosphate synthetase 1 , mitochondrial & 0.35 & 0.47 & 0.22 \\
\hline ABCG5 & ATP-binding cassette, subfamily G (WHITE), member 5 & 0.43 & 0.62 & 0.30 \\
\hline UGT2B17 & UDP glucuronosyltransferase 2 family, polypeptide B17 & 0.69 & 0.57 & 0.31 \\
\hline ABCG8 & ATP-binding cassette, subfamily G (WHITE), member 8 & 0.47 & 0.78 & 0.33 \\
\hline $\mathrm{ADH} 1 \mathrm{C}$ & alcohol dehydrogenase 1C (class I), gamma polypeptide & 0.55 & 0.68 & 0.37 \\
\hline PON1 & paraoxonase 1 & 0.63 & 0.75 & 0.48 \\
\hline
\end{tabular}

All the genes listed belong to the top down-regulated network, lipid metabolism. The mRNA fold change for each gene (fold change $>1$ for upregulated genes or $<1$ for down-regulated genes) corresponds to the ratio of mRNA expression for cells exposed to each treatment (25nM TCDD or $10 \mu \mathrm{M} \alpha$-endosulfan or their combination) versus untreated cells $(0.15 \% \mathrm{DMSO})$. The values are the means of three microarray experiments. All the genes are significantly differentially expressed with $\mathrm{p}<0.05$ by Fisher $\mathrm{t}$-test analysis. The values for gene expression following treatment with TCDD or $\alpha$-endosulfan alone are shown for comparison. 


\section{Supporting Information Legends}
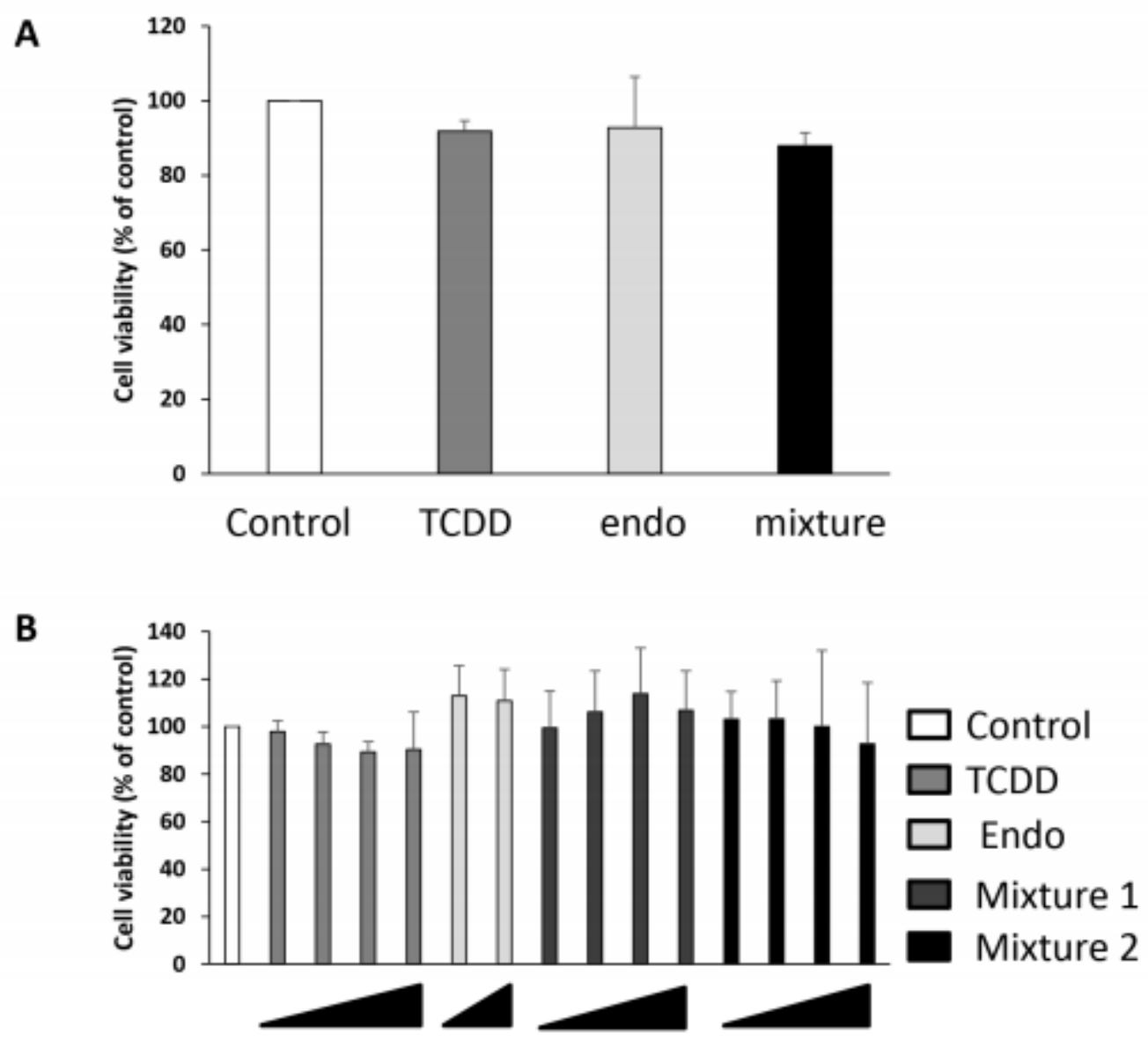

Figure S1. Cell viability after 3 or 8 days of exposure to pollutants. A. HepaRG cells (6 X $10^{4}$ cells/well in a 96 well plate) were exposed for $72 \mathrm{H}$ to the control medium or TCDD $(25 \mathrm{nM})$, or $\alpha$-endosulfan $(10 \mu \mathrm{M})$ or the mixture. B. HepaRG cells were exposed for 8 days to a range $(0.2,0.5,1$, and $5 \mathrm{nM})$ of concentrations of TCDD, to 3 or $10 \mu \mathrm{M} \alpha$-endosulfan and to the combinations of $3 \mu \mathrm{M}$ (mixture 1 ) or $10 \mu \mathrm{M}$ (mixture 2 ) $\alpha$-endosulfan with the various concentrations of TCDD (lowest to highest from left to right). Cell viability was measured in 3 (A) or 4 (B) independent experiments in triplicate using the WST-1 kit (Roche Applied Science) according to the manufacturer's instructions. The viability is expressed as the $\%$ of the control condition (100\%). No statistical difference in the viability of the cells after the various treatments was found. 

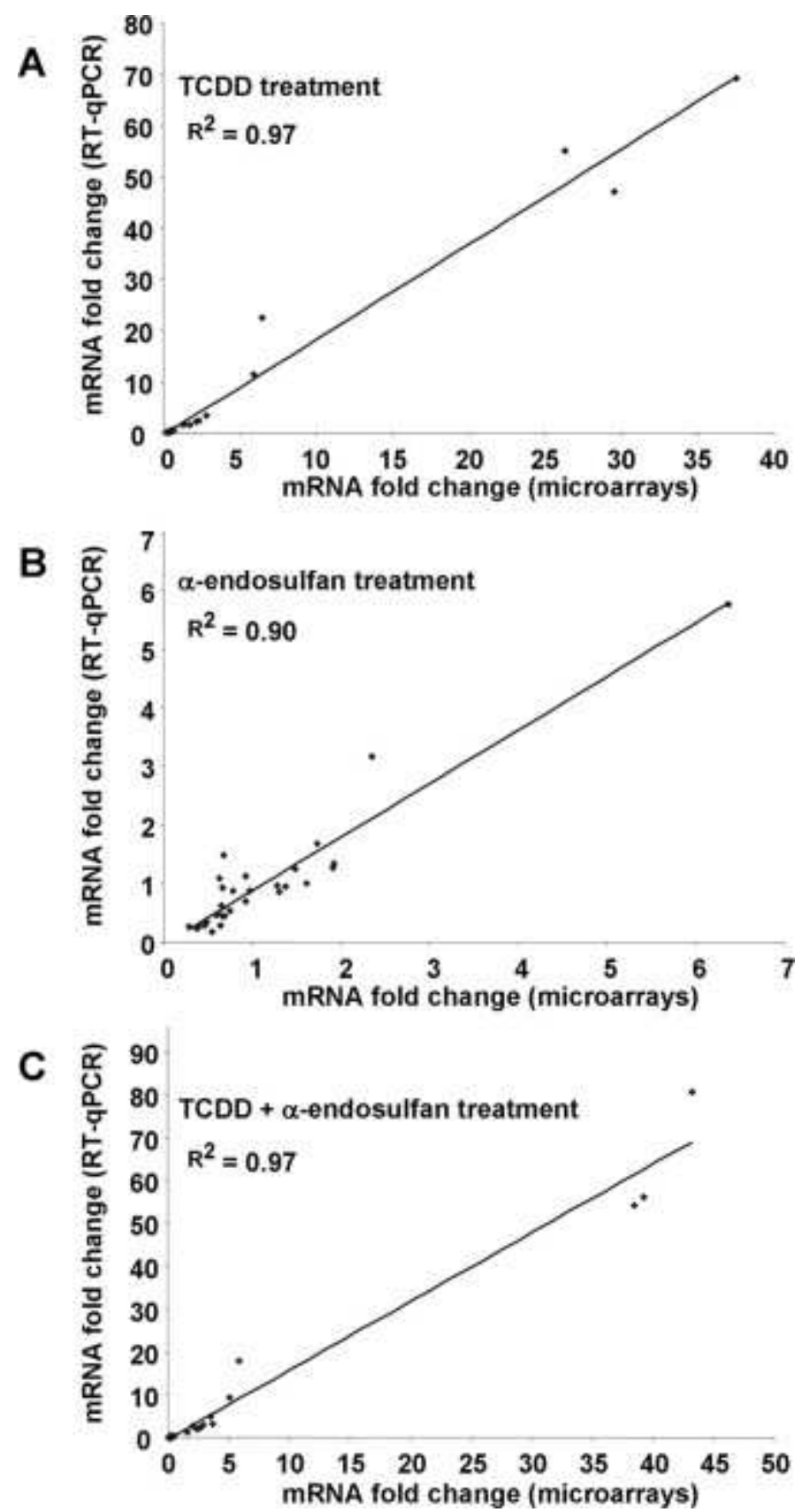

F 
Figure S2. Comparison between the levels of expression of genes as measured by microarrays and RT-qPCR. A. Comparison for the treatment with TCDD (25nM, 30H). B. Comparison for the treatment with $\alpha$-endosulfan $(10 \mu \mathrm{M}, 30 \mathrm{H})$. C. Comparison for the combined treatment with TCDD $(25 \mathrm{nM}, 30 \mathrm{H})$ and $\alpha$-endosulfan $(10 \mu \mathrm{M}, 30 \mathrm{H})$. The correlation coefficients $\mathrm{R}^{2}$ are $0.97,0.90$, and 0.97 for the treatments with TCDD, $\alpha$ endosulfan and the mixture, respectively. 

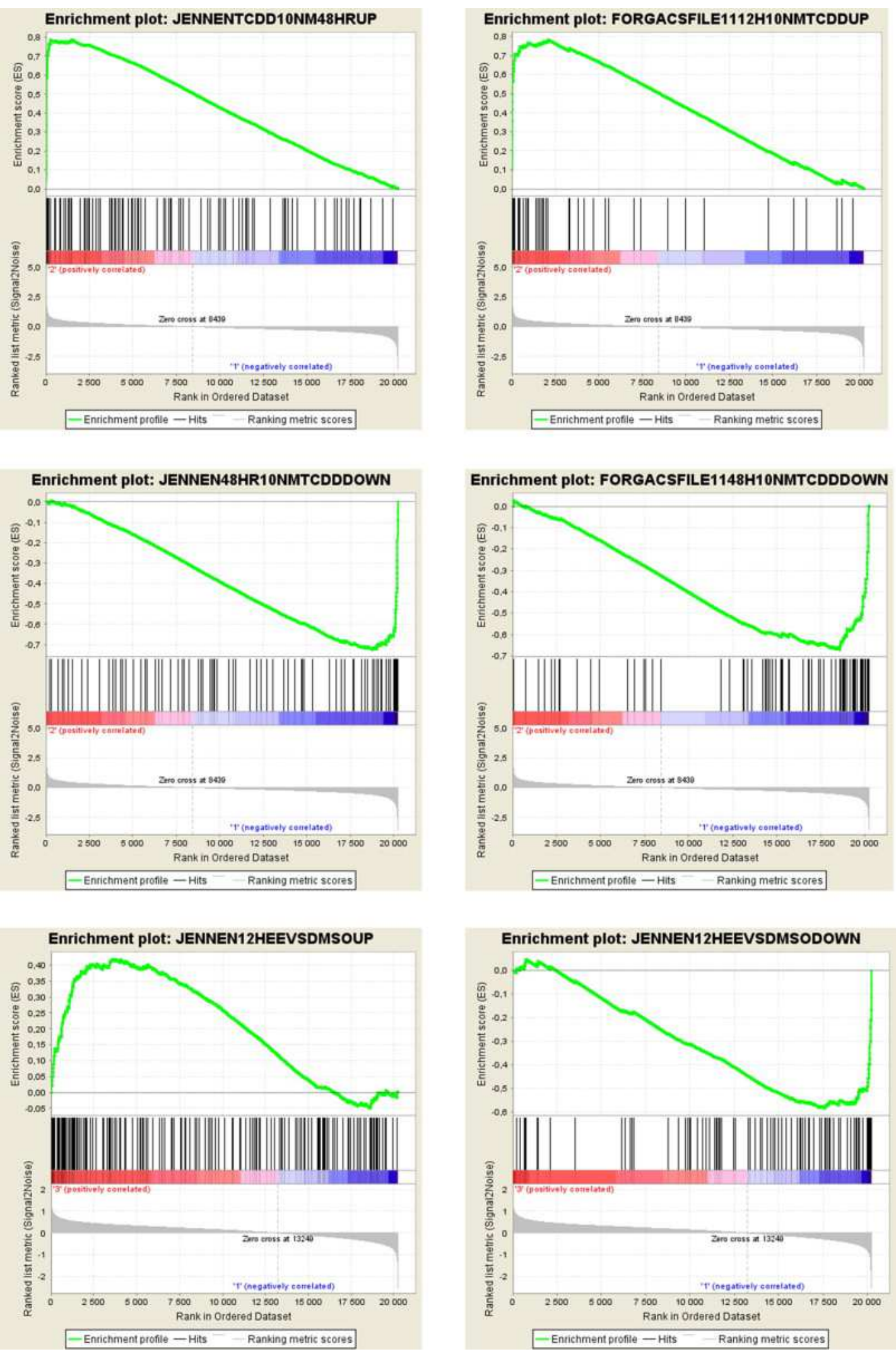

Figure S3. Gene Set Enrichment Analysis (GSEA) and Rank Rank Hypergeometric Overlap Analysis. A. GSEA plots for the gene sets up-regulated by TCDD (first row) derived 
from the data of Jennen et al. [42] (left, 10nM TCDD, 48H treatment) and Forgacs et al. [58] (right, $10 \mathrm{nM}$ TCDD, $12 \mathrm{H}$ treatment), for gene sets down-regulated by TCDD (second row) from the data of Jennen et al. [42] (left, $10 \mathrm{nM}$ TCDD, 48H treatment) and Forgacs et al. [58] (right, $10 \mathrm{nM}$ TCDD, $48 \mathrm{H}$ treatment), for gene sets up- and down-regulated by $17 \beta$-estradiol (third row) from the data of Jennen et al. [42] (left, up-regulated, right, down-regulated, 30 $\mathrm{mM} 17 \beta$-estradiol, $12 \mathrm{H}$ treatment). The abscissas correspond to the ordered list of genes that are differentially expressed for HepaRG cells treated or not by TCDD in this study. The ordinates represent the cumulative distribution (enrichment score, green line) for the cells (HepaRG or primary human hepatocytes, published data) treated or not with TCDD. The red and blue colors indicate enrichment and depletion, respectively, of genes. B. Rank rank hypergeometric overlap heat plots of expression data from this paper (abscissas) and that from Jennen et al. [42] (ordinates) for treatment with $10 \mu \mathrm{M} \alpha$-endosulfan, $30 \mathrm{H}$ and $30 \mu \mathrm{M} 17 \beta$ estradiol, $12 \mathrm{H}$, respectively (top) and for treatment with $25 \mathrm{nM}$ TCDD, $30 \mathrm{H}$ and $10 \mathrm{nM}$ TCDD, $12 \mathrm{H}$, respectively (bottom). The metric on the right represents the $\log _{10}$-transformed $\mathrm{t}-$ test P-value. Pixels with positive values (red) indicate a higher than expected number of overlapping genes and pixels with negative values (blue) indicate a lower than expected number of overlapping genes. Overlap is seen here by the orange areas. 